\title{
MRI of the Hip: Important Injuries of the Adult Athlete
}

\author{
Lauren M. Ladd • Donna G. Blankenbaker • \\ Kirkland W. Davis · James S. Keene
}

Published online: 19 April 2014

(C) Springer Science+Business Media New York 2014

\begin{abstract}
Hip pain is a common problem in adult athletes and may be caused by a wide range of acute and chronic injuries, many of which lead to prolonged time away from sport. This article highlights the magnetic resonance imaging (MRI) findings of important hip injuries in adult athletes, including select osseous, impingement, intraarticular, and musculotendinous injuries. The most commonly affected athletes, clinical presentation, and MRI findings of each injury are reviewed with corresponding clinical pearls from the orthopedist's perspective.
\end{abstract}

Keywords Hip Injuries $\cdot$ Athlete $\cdot$ Magnetic resonance imaging

\section{Introduction}

The hip is the essential and central component of movement between the torso and lower extremities and is

This article is part of the Topical Collection on Imaging of Sports Injuries.

L. M. Ladd $(\varangle) \cdot$ D. G. Blankenbaker · K. W. Davis Department of Radiology, University of Wisconsin School of Medicine and Public Health, 600 Highland Ave, Rm E3/366, Madison, WI 53792-3252, USA

e-mail: Lauren.M.Ladd@gmail.com

D. G. Blankenbaker

e-mail: dblankenbaker@uwhealth.org

K. W. Davis

e-mail: kdavis@uwhealth.org

\section{J. S. Keene}

Department of Orthopedics and Rehabilitation, University of Wisconsin School of Medicine and Public Health, 600 Highland Avenue, K4/730, Madison, WI 53792-7375, USA

e-mail: keene@ortho.wisc.edu integral to proper performance in almost all sports. Thus, hip pain in the athlete, whether recreational or elite, presents a critical challenge to performance.

The hip utilizes range of motion in all planes during ambulation and sports and acts as a center of gravity for the body during standing and movement $[1,2]$. It also bears the forces of weight-bearing, twisting, and translation on the lower extremity. It is estimated that the hip receives forces up to 3 times a person's body weight during low impact, such as walking [3], up to 5 times the body weight during jogging, and 8-12 times the body weight during contact sports [3, 4]. Complex anatomy, including the congruent femoral head and acetabulum, hyaline articular cartilage, fibrocartilaginous labrum, and surrounding muscles and tendons, is required to ensure stabilization of the hip during extreme ranges of motion and significant weight-bearing forces. Consequently, injury and pain may result from trauma, overuse, or improper function of any of these osseous or soft tissue structures.

Depending on the study and sport, the hip accounts for 3-18\% of all sports-related injuries [3-7]. Pain and dysfunction from athletic hip injuries cause significant morbidity, including the greatest time lost from sports compared to other lower extremity injuries [8] and progressive degeneration leading to early osteoarthritis or even hip arthroplasty. Given the potential consequences of hip injuries, the correct diagnosis is essential to early and appropriate treatment of the athlete and return to sports. This article will review important injuries of the hip in athletes, including osseous injuries, bony and soft tissue impingements, intra-articular pathology, and tendon and muscle injuries.

Imaging Evaluation

Radiographs are the first line imaging technique to assess the athlete with hip or groin pain. According to the American College of Radiology Musculoskeletal Imaging 
Criteria [9], magnetic resonance imaging (MRI) is the next appropriate imaging method with negative radiographs. For symptoms of generalized pain or nonspecific physical examination findings, imaging is best performed with conventional MRI of the pelvis and hip. If symptoms or clinical examination findings suggest intra-articular pathology, an MR arthrogram is considered the method of choice.

At our institution, generalized or nonspecific hip pain is evaluated with MR sequences of the entire bony pelvis, including coronal T1 and STIR and axial T1 and fat-suppressed T2 sequences with an 8-channel cardiac or 32-channel torso coil (depending on patient size), large field of view, and 5-mm slice thickness. Small field-ofview $(18 \mathrm{~cm})$ sagittal fat-suppressed proton density (PD) and coronal fat-suppressed T2 sequences are focused on the painful hip with 4-mm slice thickness.

When intra-articular pathology is suspected, MR arthrography is performed. Within 30 min following fluoroscopic injection of $12 \mathrm{ml}$ of a solution containing $5 \mathrm{ml}$ $1 \%$ lidocaine, $5 \mathrm{ml} 0.5 \%$ ropivicaine, $5 \mathrm{ml}$ iodinated contrast, $5 \mathrm{ml}$ sterile saline, and $0.1 \mathrm{ml}$ gadolinium contrast into the hip, scanning begins. Dedicated coronal fat-suppressed T1 and T2, sagittal fat-suppressed PD, axial T1 and fat-suppressed $\mathrm{T} 2$, oblique axial fat-suppressed $\mathrm{T} 1$, and radial fat-suppressed $\mathrm{PD}$ images with $22-\mathrm{cm}$ field of view and 4-mm slice thickness are obtained of the injected hip only. Although radial images were initially believed to, but subsequently proven not to [10], provide superior evaluation for labral tears, their greatest value currently is in the detection of abnormal morphology, specifically cam morphology of the femur [11].

\section{Orthopedic Pearl}

The addition of ropivacaine to intra-articular contrast is key to evaluating the significance of MR arthrogram findings. A patient may have a labral tear on an MR arthrogram. However, if they do not experience 2-3 $\mathrm{h}$ of pain relief after the arthrogram injection, then the hip joint and labral tear are not the source of their "hip pain." Labral tears have been diagnosed in 15-25\% of asymptomatic individuals [12].

\section{Osseous Injuries}

\section{Contusion}

Contusions of the hip are most commonly seen in contact sports, where a direct blow to the bone results in MR findings of bone marrow edema related to trabecular microfracture. This injury is most notable in football players at the iliac crest (known as "hip pointers") or proximal femur [13], accounting for up to $32 \%$ of contusions in a 10-year review of NFL injuries [4]. The ill-defined low T1 and corresponding high T2 signal on MRI is similar to stress reactions, but can be differentiated by patient history, physical examination findings (overlying ecchymosis), surrounding soft tissue edema on MRI, and location of the marrow abnormality [14]. Extrapolating from a study of knee contusion marrow edema, marrow signal abnormality in hip contusions may be seen as early as $1 \mathrm{~h}$, and more reliably at $6 \mathrm{~h}$, post injury [15] and may persist up to 4 months, as was seen in nearly $70 \%$ of patients in another study [16].

\section{Orthopedic Pearl}

Hematoma aspiration and corticosteroid injection of an iliac crest hip pointer will dramatically speed recovery and get the athlete back on the field.

\section{Stress Fractures}

The untrained eye may confuse stress injuries for bone contusions. However, because stress injuries may progress to complete fracture and result in prolonged recovery or career-ending complications, it is imperative to distinguish these entities and identify such injuries early [17-20]. Stress injuries are most commonly seen in endurance athletes, such as runners and military recruits, as well as recreational athletes with sudden increases in activity. Pain is worse with activity, but because the presentation is insidious, average time to diagnosis is 3.5 months [20].

Repetitive stress in these athletes stimulates bone remodeling, beginning with osteoclastic activity that is not matched by reparative osteoblastic activity and periosteal maturation, which lag 10-14 and 20 days, respectively. This causes temporary weakening of the marrow and cortical bone, making one vulnerable to microtrabecular fractures (stress reaction) and cortical failure (stress fracture) $[17,21]$. Classic MRI features include ill-defined focal or diffuse high T2 marrow signal due to microtrabecular fractures and intramedullary edema, with or without corresponding low T1 signal and/or periosteal edema. With any of these findings, one should carefully evaluate for a hypointense band in the marrow or focal cortical abnormality, indicating stress fracture and necessitating prolonged non-weightbearing or rest from sporting activity. Because of the severe consequences of undiagnosed stress fractures, we concur with others that the diagnosis of stress fracture be based on combined imaging findings of periosteal edema, endosteal edema, and high cortical signal, regardless of a visible fracture line [22] (Fig. 1). Of note, a stress fracture of the lateral margin of the femoral neck, or 


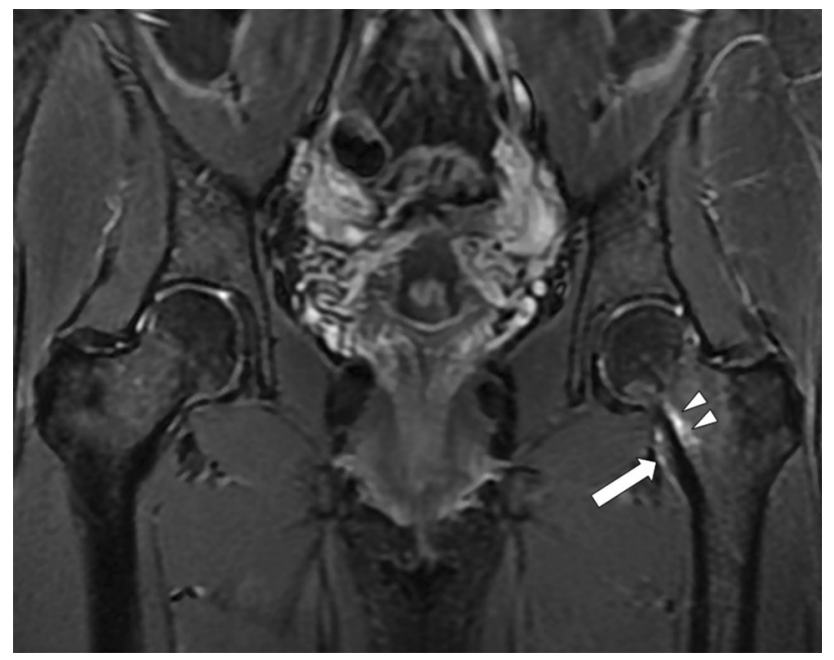

Fig. 1 A 36-year-old female runner, increasing training over 6 months, with worsening left groin pain for 4 weeks. Coronal STIR image demonstrates endosteal (arrowheads) and periosteal edema at the medial aspect of the femoral neck (thick arrow), consistent with a compressive-side femoral neck stress fracture

tensile side (Fig. 2), deserves special attention [13] as this is a "high-risk" injury that warrants urgent surgical intervention; however, some believe similar surgical fixation is warranted even for the much more common stress fractures of the medial margin, or compressive side, of the femoral neck [18].

As with contusions, bone marrow edema may persist for many months after stress fracture. Therefore, MRI is not recommended for routine assessment of healing [23], though marrow edema identified at or beyond 6 months from initial injury should be considered an ongoing or recurrent stress injury [24].

\section{Orthopedic Pearl}

A negative bone scan does not rule out a stress fracture [25]. When a tension side stress fracture is evident on MRI, the ordering physician should immediately be contacted so that the patient is warned of the consequences of weight bearing and an urgent orthopedic consultation can be arranged.

\section{Hip Dislocation and Subluxation}

Hip dislocation and subluxation are rare in athletes, but occasionally occur during high-velocity contact sports, such as football, rugby, skiing, martial arts, and gymnastics [26-28]. Approximately $90 \%$ of all sports-related dislocations are posterior and due to force against the flexed knee while in hip flexion, adduction, and/or internal rotation, as with forceful forward falls onto the knee with a flexed hip [22, 27]. These patients experience immediate

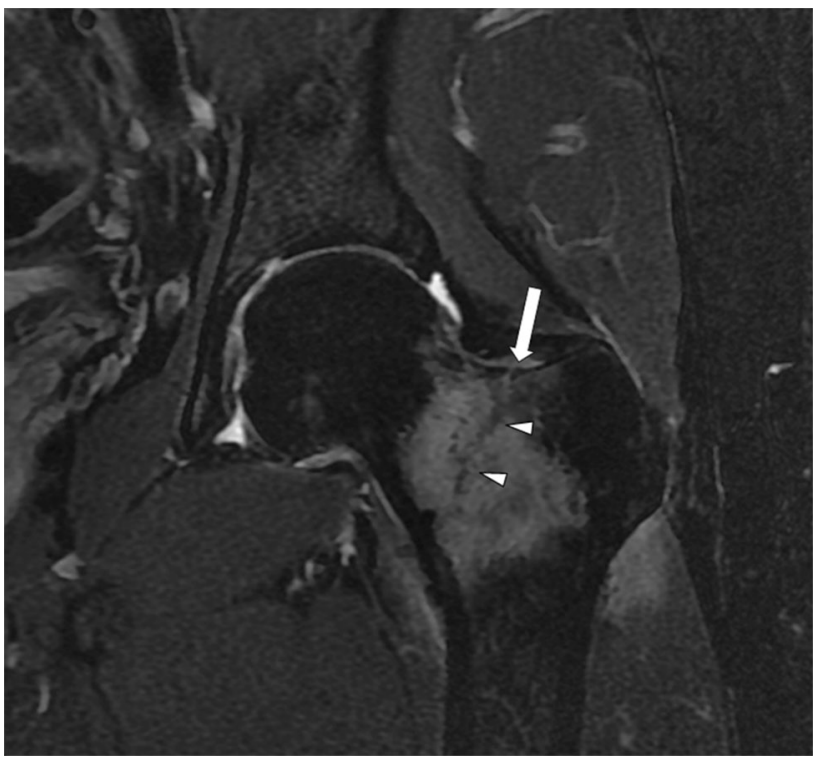

Fig. 2 A 56-year-old male runner, averaging 45-50 miles per week, with worsening hip and groin pain for 1 month. Coronal STIR image shows a near-complete stress fracture, which originates from the lateral margin (thick arrow), or tensile side, with marked femoral neck edema and a hypointense fracture line nearly completely traversing the femoral neck (arrowheads)

pain, deformity, and limited range of motion, and demonstrate a shortened, adducted, internally rotated lower extremity, allowing prompt clinical diagnosis. Anterior dislocations (Fig. 3) are extremely rare and are caused by forced abduction and/or external rotation of the flexed hip [26].

Clinical examination is typically diagnostic, but initial management includes radiographs to assess alignment and associated fractures, followed by post-reduction CT for evaluation of displaced fractures and/or articular bodies $[13,29]$, which may lead to early hip degeneration. Although CT is the typical choice, MRI provides greater detail of the resultant articular pathology and surrounding soft tissue injuries [26, 27]. According to Laorr et al. [30], the most consistent acute MRI findings following posterior hip dislocation are joint effusion or hemarthrosis (100\%), surrounding muscle injury (50-100\%, greatest in the gluteal and medial compartments), and iliofemoral ligament injury ( $85 \%)$. Less consistently, intra-articular bodies $(30 \%)$, labral tears $(7 \%)$, and ligamentum teres entrapment $(7 \%)$ were identified. Further, an arthroscopic study of professional athletes following hip dislocation by Philippon et al. [31] found labral tears and chondral injuries in all athletes, intra-articular bodies and at least partial ligamentum teres tears in most (78\%), and capsular tears in a few (14\%). Thus, MRI may help dictate the need for surgical management. 


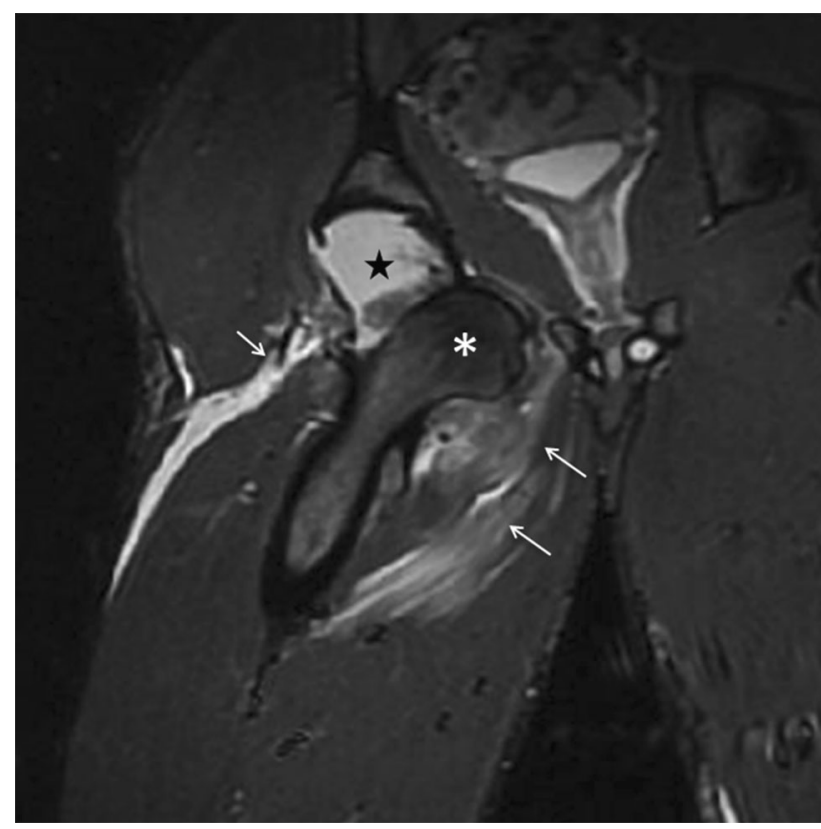

Fig. 3 A 16-year-old male football player with traumatic injury who presented to the orthopedic clinic the day after injury. Coronal STIR image of anterior inferior dislocation of the femoral head (asterisk), positioned caudal to a fluid- and blood-filled acetabulum (star) and abutting the obturator ring. Associated myotendinous strains and tears are noted (arrows)

Although a less severe injury, traumatic subluxation may also lead to similar intra-articular pathology and require careful treatment to prevent joint damage. Subluxation may result from similar mechanisms of dislocation, as well as from minor trauma in individuals with intrinsic hypermobility or rotational instability due to congenital or postsurgical labral deficiency [13, 27]. Accordingly, in addition to contact sport athletes at risk for dislocation, athletes who perform repetitive hip rotation and axial loading, such as ice skaters, ballerinas, baseball players, and advanced golfers, are at risk for subluxation [27].

Hip subluxation is often difficult to diagnose clinically because of the lack of clear history or physical examination findings [27]. Consequently, MRI may be necessary to make the accurate diagnosis. The best known triad of MRI findings includes hemarthrosis, posterior acetabular lip fracture, and iliofemoral ligament disruption [32]. Additional variable findings mirror those of hip dislocations, including femoral head contusion, chondral injuries, labral tears, capsular disruption, and ligamentum teres ruptures $[13,33,34]$.

MRI may be used after dislocations and subluxations as routine follow-up, or importantly in the setting of new pain, to monitor for osteonecrosis $[13,22,26,35]$. From a longitudinal study of 14 patients following traumatic hip dislocation, Poggi et al. [35] found that femoral head bone marrow signal abnormality (low $\mathrm{T} 1$, high $\mathrm{T} 2$ signal) may indicate early changes of osteonecrosis. Thus, routine MRI is recommended at 4-6 weeks following injury. If signal abnormality is identified, repeat imaging should be performed after 3 months of additional therapy [35]. If the abnormality resolves on repeat imaging, it is attributed to transient edema or prolonged contusion, and sporting activity may be slowly resumed [3, 13, 22, 35]. Alternatively, if the abnormality persists, it is classified and treated as osteonecrosis [35].

\section{Orthopedic Pearl}

If intra-articular bodies are identified on pre- or postreduction CT scans, the ordering physician should immediately be notified so that the patient's weight-bearing is limited and an urgent orthopedic consultation with a hip arthroscopist is arranged.

\section{Impingement}

\section{Femoroacetabular Impingement (FAI)}

Femoroacetabular impingement is a bony impingement characterized by abnormal contact between the acetabulum and femoral head-neck junction. The bony abnormality may originate at the femoral head-neck junction (cam FAI) (Fig. 4), acetabular rim (pincer FAI) (Figs. 5, 6, 7), or both (mixed) (Fig. 8). Imaging studies demonstrate a significant predominance of mixed FAI, ranging from 62 to $86 \%$ of all patients with FAI $[36,37]$, but the majority of athletes treated arthroscopically have cam FAI [37, 38•].

Because of its role in development of early osteoarthritis, the screening, diagnosis, and management of FAI has received much attention over the past 15 years [39]. Athletes are at greater risk for these degenerative changes because of the exertional forces beyond normal physiologic limits superimposed on bony abnormalities [40]. Athletes who perform repetitive or extreme flexion and/or internal rotation are predisposed to impingement [39] and include hockey players, golfers, dancers, football players, and soccer players [37].

The bony contact of FAI results in abnormal force on the intervening tissues, specifically the labrum and articular cartilage, leading to progressive intra-articular damage. This results in insidious, nonspecific anterior hip pain, which is greatest with maximal flexion and extension against resistance, and may be accompanied by a long history of decreased flexibility [40, 41]. Likewise, athletes may have difficulty with squatting, pivoting, or lateral cutting movements because of the early bony contact at the 

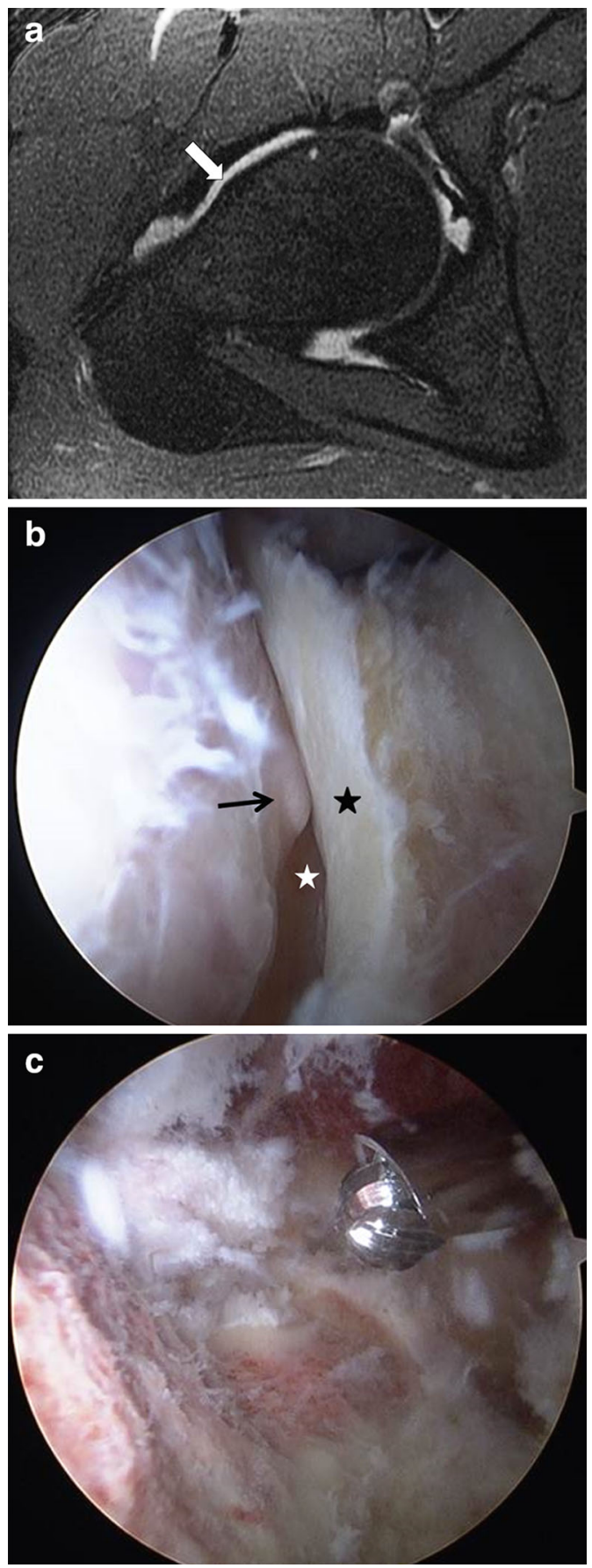

Fig. 4 a A 21-year-old collegiate basketball player with progressively increasing anterior hip pain. Oblique axial T1 fat-suppressed MR arthrogram image demonstrates an abnormal femoral head-neck junction osseous bump (arrow) of cam FAI. Alpha angle measured $65^{\circ}$. Arthroscopy confirmed a cam osteophyte with an associated anterior labral tear, both of which were excised. b, c Representative arthroscopic image from a different patient with cam FAI undergoing surgical removal. b Arthroscopic view of an osseous bump at the femoral head-neck junction (arrow) in frog leg position. The femoral neck (white star) is below and to the right of the bump, and the hip joint capsule (black star) is abutting the bump. c Arthroscopic images of the femoral head-neck junction following bump removal

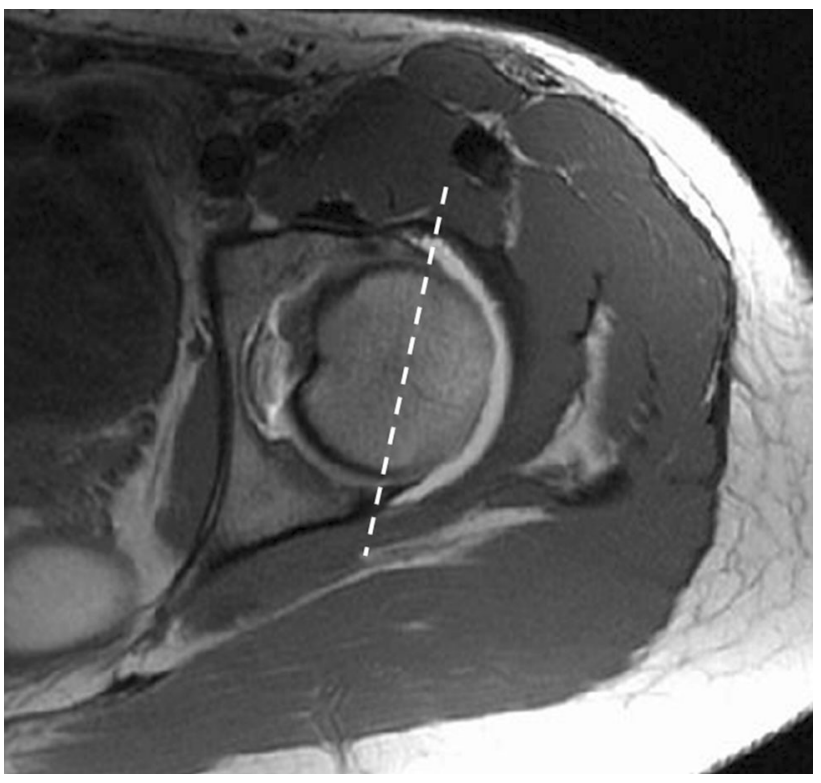

Fig. 5 A 16-year-old female former volleyball player who stopped all sports because of the sensation of her hip "popping out of the joint." Axial T1 image demonstrates lateral projection of the anterior acetabular rim compared to the posterior rim (dotted line), consistent with acetabular retroversion, a cause of pincer FAI

anteromedial hip during normal range of flexion and internal rotation [41].

The mechanism and consequent intra-articular injury depend on the FAI morphology. In cam FAI, the abnormal morphology ranges from a focal bony prominence at the anterior femoral head-neck junction to a generalized decrease in femoral head-neck offset [42]. This prominent head-neck junction abnormally contacts the acetabular rim when the hip is flexed and/or internally rotated. The point of contact is typically at the chondrolabral junction, resulting in focal shearing of the articular cartilage. If this trauma continues, secondary degeneration of the labrum eventually occurs [43].

In pincer FAI, there is abnormal bony contact of the femoral neck upon the acetabulum during flexion and/or internal rotation due to acetabular prominence. Implicated types of abnormal acetabular morphology include congenital retroversion (Fig. 5), os acetabuli (Fig. 7), postsurgical acetabular overcoverage (acetabular osteotomy), and acetabular protrusio [22, 40]. In contrast to cam FAI, though, pincer FAI incites primary labral degeneration due to compression as the prominent acetabulum contacts the femoral neck, followed by eventual articular cartilage failure [40, 43]. Pincer impingement is also caused by a prominent anterior inferior iliac spine as discussed below. Patients with pincer impingement may have contra coup articular cartilage lesions (inferior quadrant chondrosis) caused by the head being levered and forced against the 

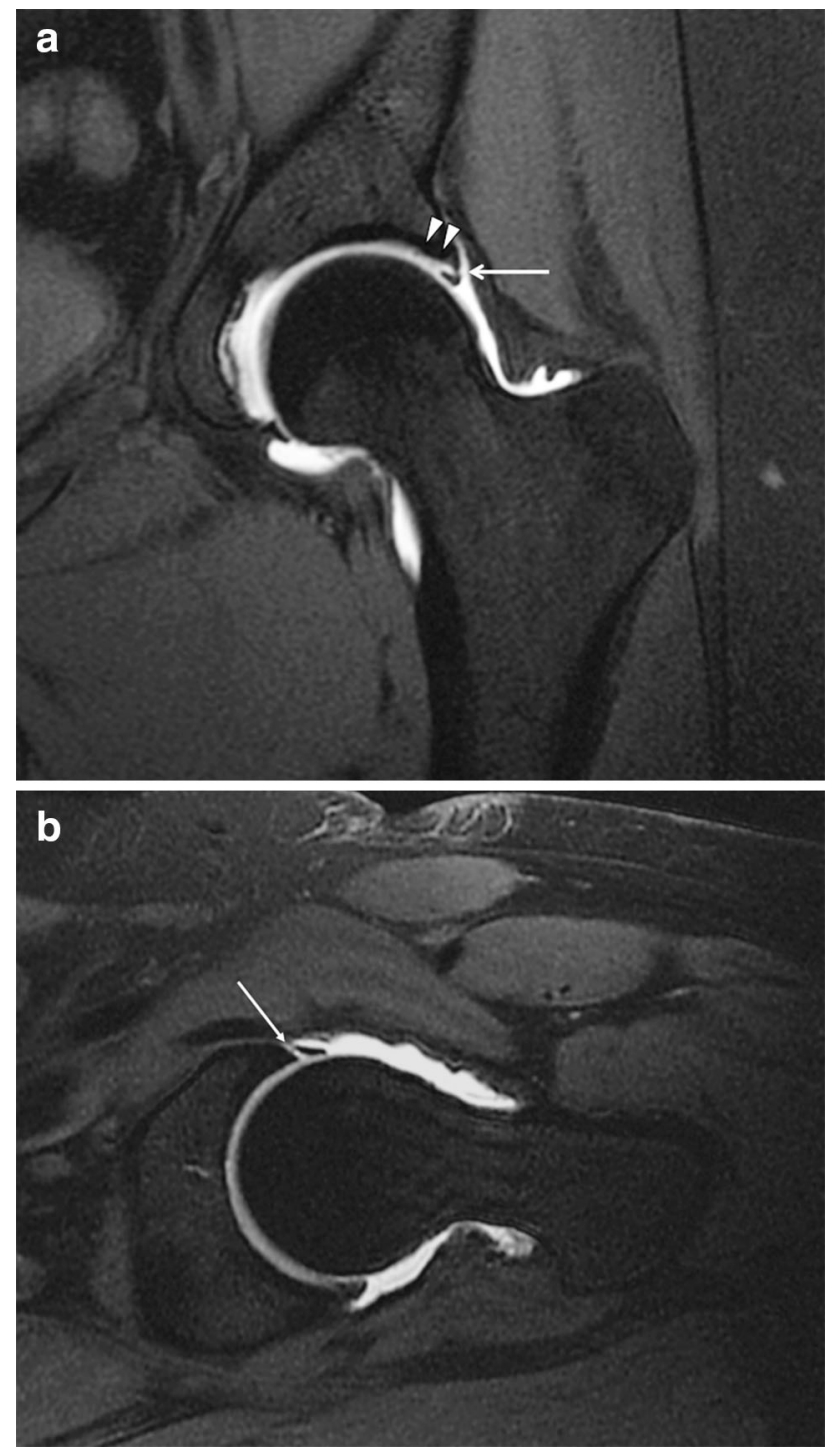

Fig. 6 A 29-year-old female with 1 year of progressive hip pain. a Coronal T1 fat-suppressed MR arthrogram image exhibits bony prominence of the lateral acetabular rim (arrowheads), consistent with pincer morphology, with an associated anterosuperior labral tear (long arrow). Note relatively little chondral damage at this stage. b Oblique axial T1 fat-suppressed MR arthrogram image best depicts the associated anterosuperior labral tear (long arrow)

posterior acetabulum when the anterior pincer abutment occurs [43-45].

Although radiographs are the first line in imaging FAI, radiographic measurements and features of FAI are beyond the scope of this article. MRI enables assessment of osseous morphology, similar to radiographs, and also of intra-articular consequences of impingement, specifically labral and chondral injuries. The osseous bump of cam impingement (Fig. 4) is typically assessed on oblique axial images. Despite the debate about the accuracy and reliability of the alpha angle, or even what measurement is abnormal (most designate abnormal as $>55^{\circ}$ ), it remains the preferred objective measurement to suggest cam FAI [22, 44, 46, 47] and was the only independent predictor of hip pain in elite football players [48], reiterating the importance of its role in diagnosis of FAI and early intervention. Beyond the alpha angle, radial images may further identify osseous bumps that are not directly anterior and would have otherwise been missed on oblique axial images [11].

In pincer FAI, conditions causing acetabular overcoverage lead to varied morphology in several locations. Acetabular retroversion (Fig. 5) is best identified on axial images, where the anterior acetabular wall projects lateral to the posterior wall superiorly. Generalized overcoverage, due to protrusio or a hypertrophic rim of osteophytes (Fig. 6), is also visualized on axial images, where the center of the femoral head projects medial to a line connecting the anterior and posterior acetabular walls [45]. Lastly, focal overcoverage by an os acetabuli (Fig. 7) is best seen on coronal images. Secondary signs, specifically anterior acetabular subchondral edema, help draw attention to pincer FAI and acetabular overcoverage [40, 44].

In addition to osseous abnormalities, common associated findings of FAI in radiology-surgical correlation studies include labral and/or chondral injuries, indentified in $97 \%$ of patients with FAI in one surgical series [45, 46, 49]. These intra-articular abnormalities are best evaluated with MR arthrography, as will be discussed later, and are dependent on the underlying bony abnormality. Cam FAI causes larger focal cartilage lesions, ranging from partial thickness cartilage loss to delamination tears (fluid or contrast undermining the articular cartilage) at the anterosuperior acetabulum where impingement occurs (Fig. 8) $[44,46]$. Initially, the labrum is simply displaced laterally, but with continued impingement, it may progress to tears, characteristically a perpendicular gap at the chondrolabral transition zone [45, 46, 49]. Conversely, in pincer FAI, labral damage (Fig. 6) is the primary injury and is typically a tear perpendicular to the labral articular surface or generalized high intrasubstance signal of degeneration. Continued impingement results in secondary cartilage loss (Fig. 7), classically as a thin rim along the chondrolabral transition zone and smaller than the lesions of cam FAI $[44,45]$.

In general, chondrolabral abnormalities are treated arthroscopically, as is FAI morphology (Fig. 4b, c) [38•]. Thus, recognition of causative FAI morphology when chondrolabral injuries are present is crucial to ensure concurrent surgical management and prevention of progressive joint damage. Several surgical studies have shown that $86-95 \%$ of high-level athletes arthroscopically treated for FAI return to play at competitive levels $[37,38 \bullet$, 50], supporting the importance of proper identification of FAI and associated injuries in the successful management of these athletes. 

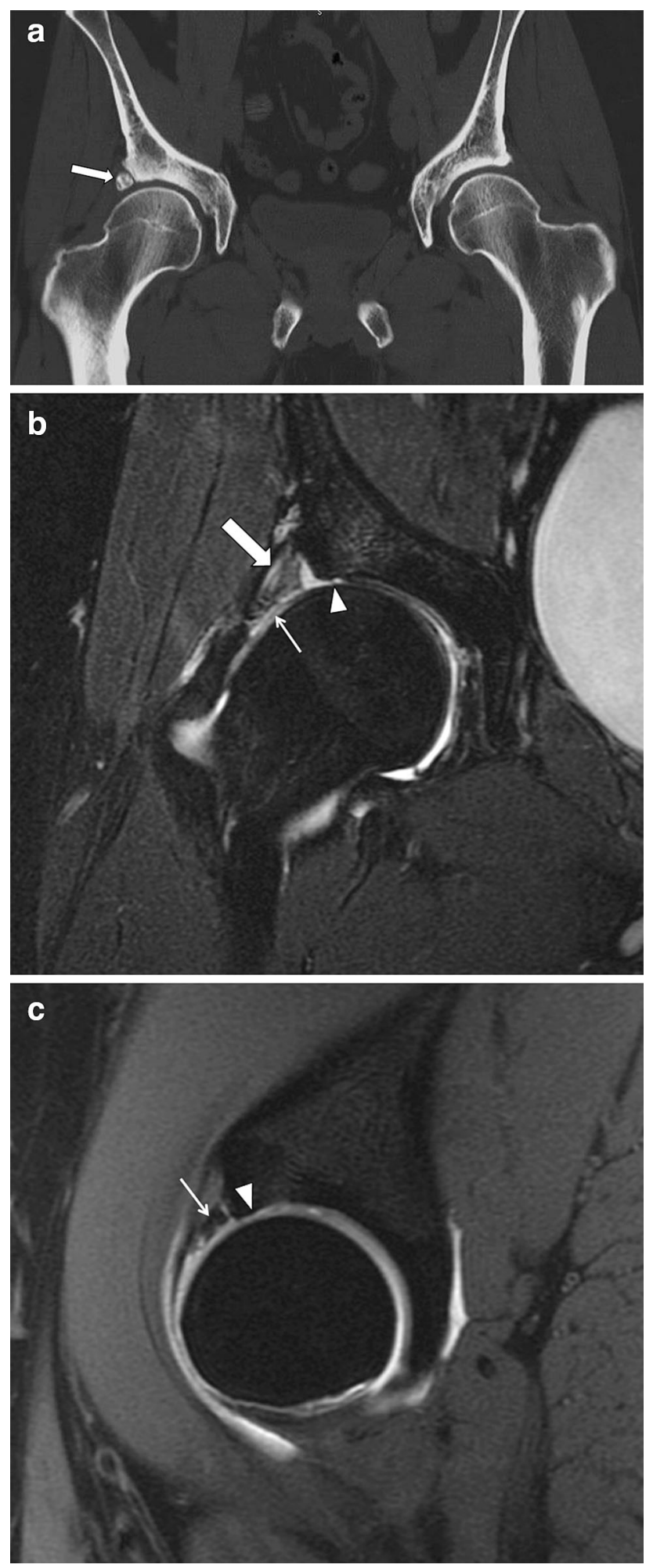

\section{Orthopedic Pearl}

Many athletes ( $\sim 67 \%$ in elite soccer players [51]) have impingement bony morphology (increased alpha angle, decreased head-neck offset, etc.), but are asymptomatic.
4Fig. 7 A 42-year-old male with a long history of anterior right hip and groin pain, limiting his ability to exercise. a Coronal CT image clearly shows a large ossicle along the superolateral acetabular rim, consistent with an os acetabuli (arrow). b Coronal T2 fat-suppressed MR arthrogram image demonstrates the os acetabuli at the superolateral acetabulum (thick arrow). Note the difficulty discerning the osseous origin of this structure and possible confusion for an abnormal labrum. There is also a peripheral degenerated labrum (thin arrow) and an associated focal full-thickness chondral defect superolaterally (arrowhead). c Sagittal T1 fat-suppressed MR arthrogram image showing an anterior os acetabuli mimicking a torn labrum (arrow) and focal anterosuperior chondral thinning (arrowheads) as sequelae of the os acetabuli and pincer FAI

However, the most common reason for repeat hip arthroscopies is untreated or inadequately treated cam and/or pincer impingement.

\section{Femoral Antetorsion}

Another bony impingement may result from abnormal proximal femoral rotation, or femoral antetorsion. Normally, there is slight anterior angulation of the femoral neck axis with respect to the posterior margin of the distal femoral condyles. Decreasing this angle, or decreased femoral antetorsion, yields a narrow anterior femoral neckacetabulum interval [52.] and gives way to early anterior bony impingement and limited internal rotation. The impaction is similar to that of the proximal femur and acetabulum during hip flexion and internal rotation in FAI and may result in similar anterior impingement symptoms $[52 \bullet, 53 \bullet, 54,55]$. These findings often present in young athletes, similar to FAI, because of increased stress and supraphysiologic movements related to sports activities [52•]. Although no studies have documented specific atrisk athletes, the causative mechanism predisposes athletes with decreased antetorsion who repeatedly or forcefully flex and internally rotate the hip, such as soccer players, dancers, and martial artists, to this impingement.

Antetorsion is defined by the angle between the line tangent to the posterior femoral condyles and the femoral neck axis (a transverse line between femoral head center and the femoral neck center at its base). To measure the antetorsion angle, axial T1-weighted MR images of the hip, from the femoral head to the femoral neck base, and of the distal femoral condyles are necessary. Many studies have demonstrated a wide and overlapping range of antetorsion angles in symptomatic and asymptomatic patients; therefore, abnormal values are not clearly established [53•, 56, 57]. Nonetheless, it is believed that antetorsion angles $<10-20^{\circ}$ may be abnormal $[52 \bullet, 54,56,57]$. As seen with FAI, impingement of decreased antetorsion may cause secondary anterior chondrolabral injuries. The overlap of symptoms, mechanism, and associated findings with FAI has led to debate if decreased antetorsion is a cause of FAI 

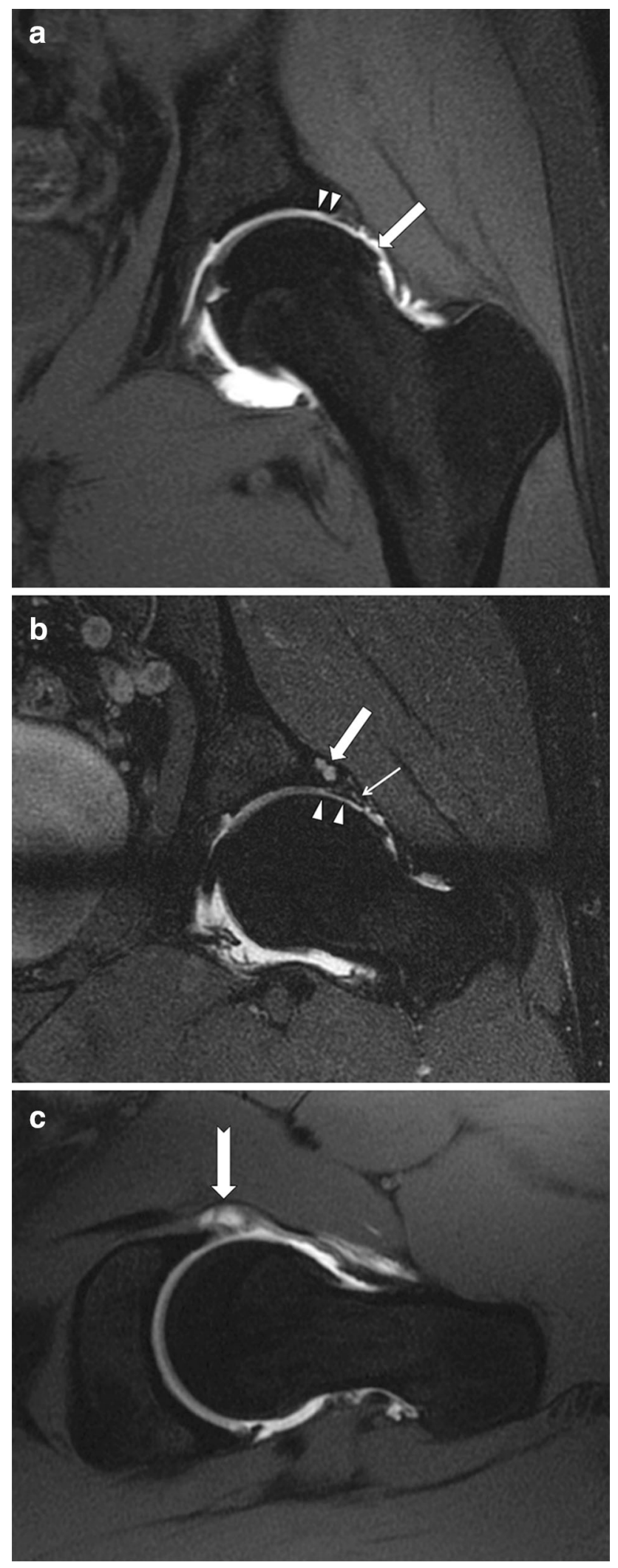

[55] or a separate impingement [52•, 54]. Regardless, assessment of femoral torsion should be considered when imaging athletes with impingement symptoms and may
4 Fig. 8 A 32-year-old athletic male and former collegiate hockey player with 1 year of anterior hip and groin pain. a Coronal T1 fatsuppressed MR arthrogram image of a prominent lateral acetabular rim (arrowheads) and osseous bump (arrow) at the femoral head-neck junction, consistent with mixed cam and pincer morphology. b Radial proton density fat-suppressed MR arthrogram image further depicts the prominent lateral acetabular ridge, femoral head-neck osseous bump, and resultant labral degeneration (thin arrow), relatively large anterior and superior chondral injury (arrowheads), and acetabular subchondral cyst formation (thick arrow). c Oblique axial T1 fatsuppressed MR arthrogram image of a multiloculated paralabral cyst (notched arrow) secondary to the complex anterosuperior labral tear. The alpha angle measures $62^{\circ}$

alter surgical management when appropriately identified $[52 \cdot, 55,57]$.

\section{AIIS/Subspine Impingement}

Initially described by Pan et al. [58, 59], in 2008 as part of a spectrum of FAI, anterior inferior iliac spine (AIIS) or subspine impingement is an extra-articular impingement, causing pain and limited range of motion in athletes. A prominent AIIS, either congenitally or due to prior trauma or surgery, may directly contact the anterior inferior femoral neck during flexion with or without internal rotation, resulting in bony impingement [53•, 59-61]. There is a natural prominence of this impingement in athletic males who have had prior rectus femoris injuries (Fig. 9) or "sprinter's fractures" from repetitive or forceful rectus femoris contraction. Therefore, this entity is seen most often in soccer players, as well as football kickers and sprinters [53•, 58, 59, 62]. Presenting symptoms include chronic or insidious anterior hip or groin pain with hip flexion, an anterior hip "grinding" sensation with flexion and lateral movements, limited flexion (generally $<105^{\circ}$ ), and tenderness to palpation directly over the AIIS [53•, 58, $59,61,62]$.

There is a focus on radiographic and CT evaluation in the limited literature describing imaging findings of AIIS impingement, including a prominent AIIS (ranging from the prominent distal anterior ilium to caudal extension beyond the acetabular rim), sclerosis of the anterior acetabular rim, and cystic change of the distal anterior femoral neck [53•, 59, 62]. To date, no studies have detailed the MRI findings of this entity. However, we believe the radiographic and CT abnormalities, as well as the classification system by Hetsroni et al. [60••] correlating morphology with symptoms and surgical candidacy, can be applied to MRI. MRI evaluation would include a search for abnormal prominence or irregular AIIS configuration (Fig. 9c), T1 and T2 hypointensity (sclerosis) of the anterior acetabular rim, high T2 signal (edema and cysts) of the anterior distal femoral neck, and thickening of the direct head rectus femoris tendon with or without intrasubstance 

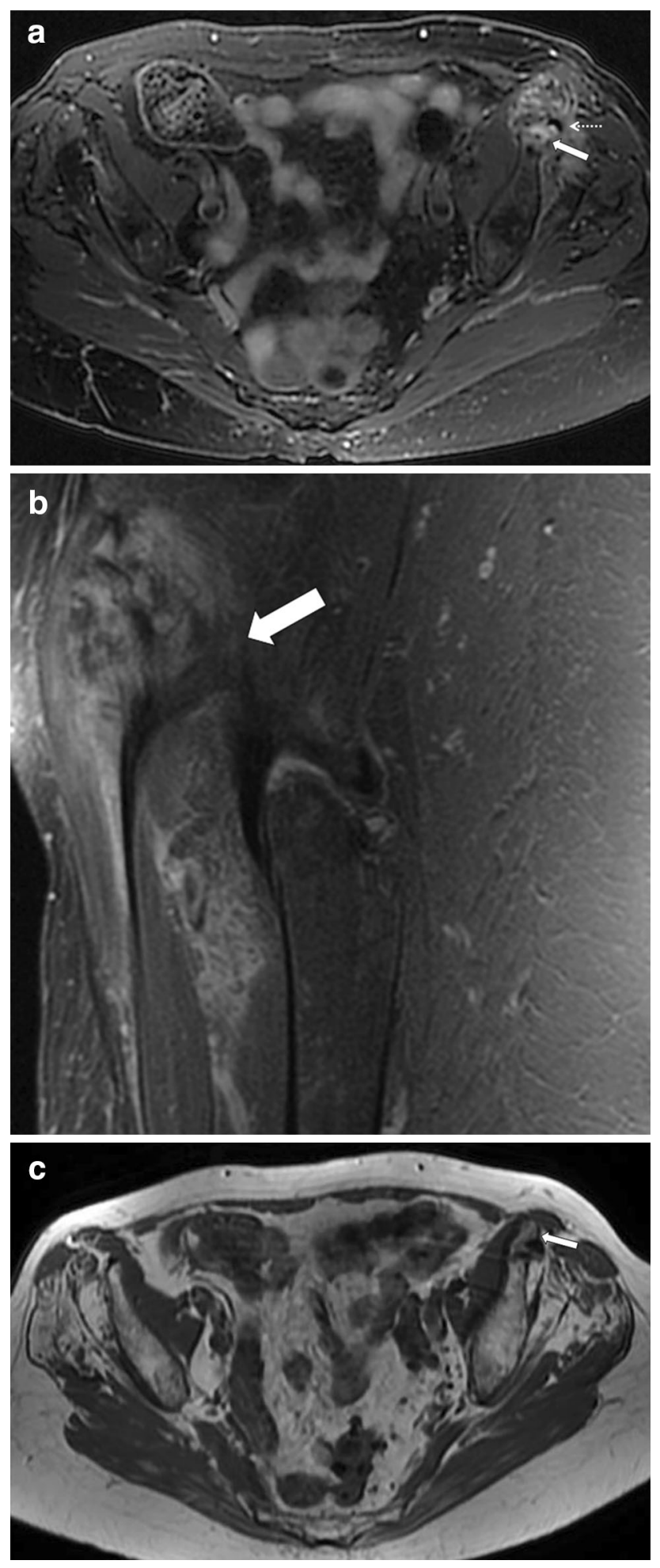

hypointensity (heterotopic ossification). The known high prevalence of concomitant FAI, identified in nine of ten patients in one study [53•, 62], should prompt close evaluation of imaging findings to discern co-existent impingements.
4 Fig. 9 An 87-year-old man with a history of a fall while walking and severe left-sided hip pain. a Axial STIR image of an acute traumatic rectus tendon avulsion shows bone marrow edema of the anterior inferior iliac spine (thick arrow) and a detached hypointense proximal rectus femoris tendon (dashed arrow) with surrounding heterogeneous edema and hemorrhage near the rectus femoris origin. b Sagittal proton density fat-suppressed image of at least partial detachment of the proximal rectus femoris direct head tendon (thick arrow) with surrounding intramuscular edema and hematoma from the acute tendon avulsion. c Follow-up axial T1 image shows the chronic sequelae of prior rectus femoris avulsion with bony overgrowth of the anterior inferior iliac spine (arrow), which may result in AIIS/ subspine impingement

Surgical decompression has been proven effective and safe in recent studies with several case reports specifically documenting resolution of symptoms, significantly improved range of motion $\left(>20^{\circ}\right)$, and ability to return to sports in nearly all postoperative athletes [58, 59, 62, 63]. Because surgical decompression can be curative, it is important to consider this impingement syndrome in athletes with hip pain, including those with other abnormalities such as FAI.

\section{Intra-Articular}

\section{Labrum}

Labral injuries are an important cause of hip pain, particularly in athletes. Recognition of labral injuries is critical because of potential treatability and prevention of early onset osteoarthritis. A brief discussion of normal labral anatomy, variants, and age-related changes is warranted to distinguish them from pathology. First, the labrum is a hypointense fibrocartilaginous structure at the bony acetabular margin. Although hypointense, there are areas of the labrum where high signal is normal and should not be mistaken for tears. Along the articular surface at the chondrolabral junction, there is a mildly hyperintense 1-2$\mathrm{mm}$ transition zone with the articular cartilage. A small, hyperintense fluid-filled cleft may also be seen at the chondrolabral junction in up to $20 \%$ of individuals because of a normal variant sublabral sulcus, recognized in surgical literature and found in any quadrant, though most commonly posteroinferiorly [64]. Similarly, irregular high signal at the inferior labrum and transverse ligament junction represents a normal labroligamentous sulcus [64].

In general, the labrum is a triangular structure, though $20-40 \%$ of asymptomatic patients have a rounded or irregular configuration [65]. Additionally, depending on the cadaveric study, the labrum may be absent in 1-15\% of patients $[65,66]$. These variations from the expected triangular shape have been correlated with increasing age, suggesting typical degeneration. Likewise, the expected 

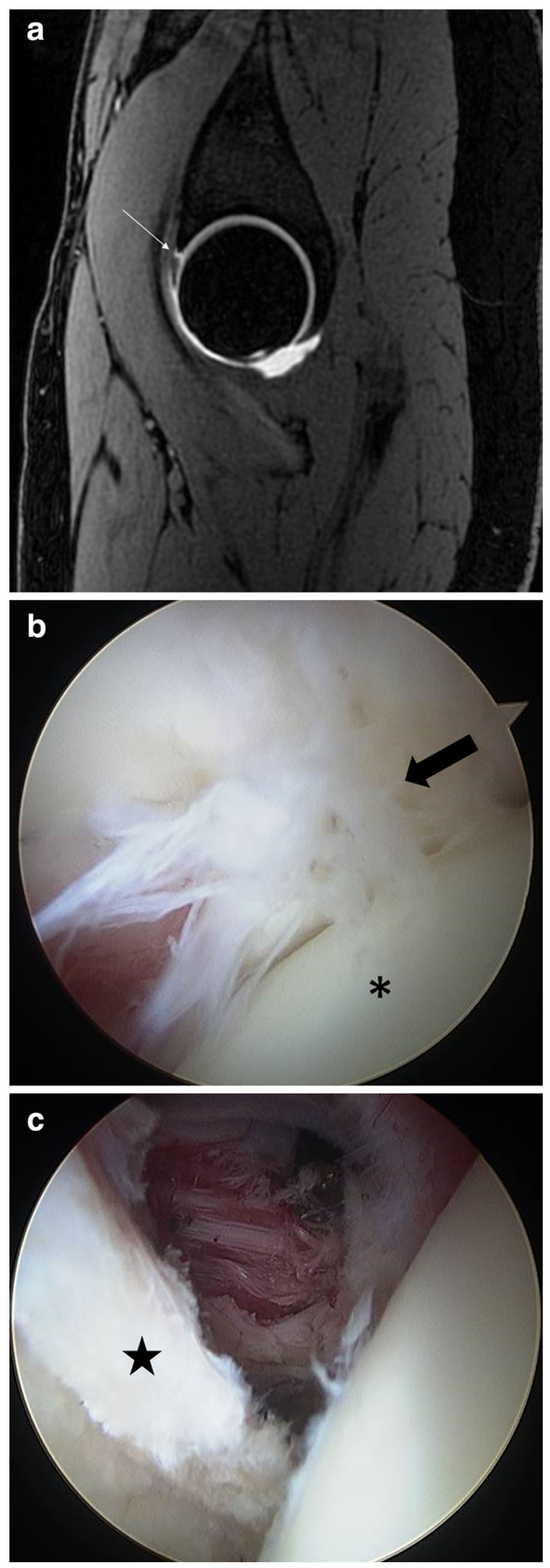

4Fig. 10 a A 27-year-old female physical therapist with progressively worsening anterior hip pain and locking, exacerbated by walking and hiking. Sagittal 3D spoiled gradient echo (SPGR) MR arthrogram image demonstrates an arthroscopically proven complete anterior labral tear (arrow). b Representative arthroscopic image of a different patient with a similar acetabular labral tear (arrow) and adjacent femoral head (asterisk). c Same arthroscopy patient after removal of the labral tear, demonstrating a smooth postoperative labrum (black star)

hypointense signal of this fibrocartilage may also vary and demonstrate increased intrasubstance signal in up to $44 \%$ of asymptomatic patients, also demonstrating a corresponding increase with patient age [65].

Although the labrum has been described as increasing the acetabular surface area by $28-60 \%$ [66, 67], its role in joint stability and weight-bearing is not clear [66, 67]. Nonetheless, extreme range of motion, particularly in hip flexion with external rotation, as well as forceful axial loading in the flexed position, may force the labrum to assist in weight-bearing, placing athletes who perform such movements at risk for labral injury. These athletes include gymnasts and dancers who utilize wide ranges of motion, soccer players and kicking athletes who perform hyperextension with external rotation, and golfers and hockey players who perform repetitive external rotation or twisting motions $[22,66]$.

Additional causes of labral tears include underlying bony abnormality (hip dysplasia or FAI morphology), anterior capsule hypolaxity, and idiopathic or age-related tears $[64,67]$. Of these, the most important in athletes is the presence of FAI morphology. The relationship between FAI morphology and labral tears has been well documented in studies of many athletes, including rowers, football players, and dancers [4, 68, 69]. A study of 31 patients with labral tears demonstrated abnormal bony morphology in $87 \%$ [68]. Thus, labral pathology should be considered in any athlete with radiographic bony morphologic abnormalities.

Labral tears result in greater loss of time from sports than other hip injuries [8]. Presenting symptoms may be acute or insidious and include anterior hip pain, which is worsened by flexion and internal rotation (impingement position) and persists or worsens over time. Another important sign in many labral tears is a painful clicking or catching sensation $[8,22,66,69]$. Impingement testing is relatively inaccurate, demonstrating a $50 \%$ false-positive rate in one study [8]. Thus, imaging plays a crucial role in diagnosis and prompt treatment.

Czerny's landmark study of labral tear detection demonstrated strong evidence that MR arthrography is far superior (90\% sensitivity, $91 \%$ accuracy) to conventional MR (30\% sensitivity, $36 \%$ accuracy) [70], although the 

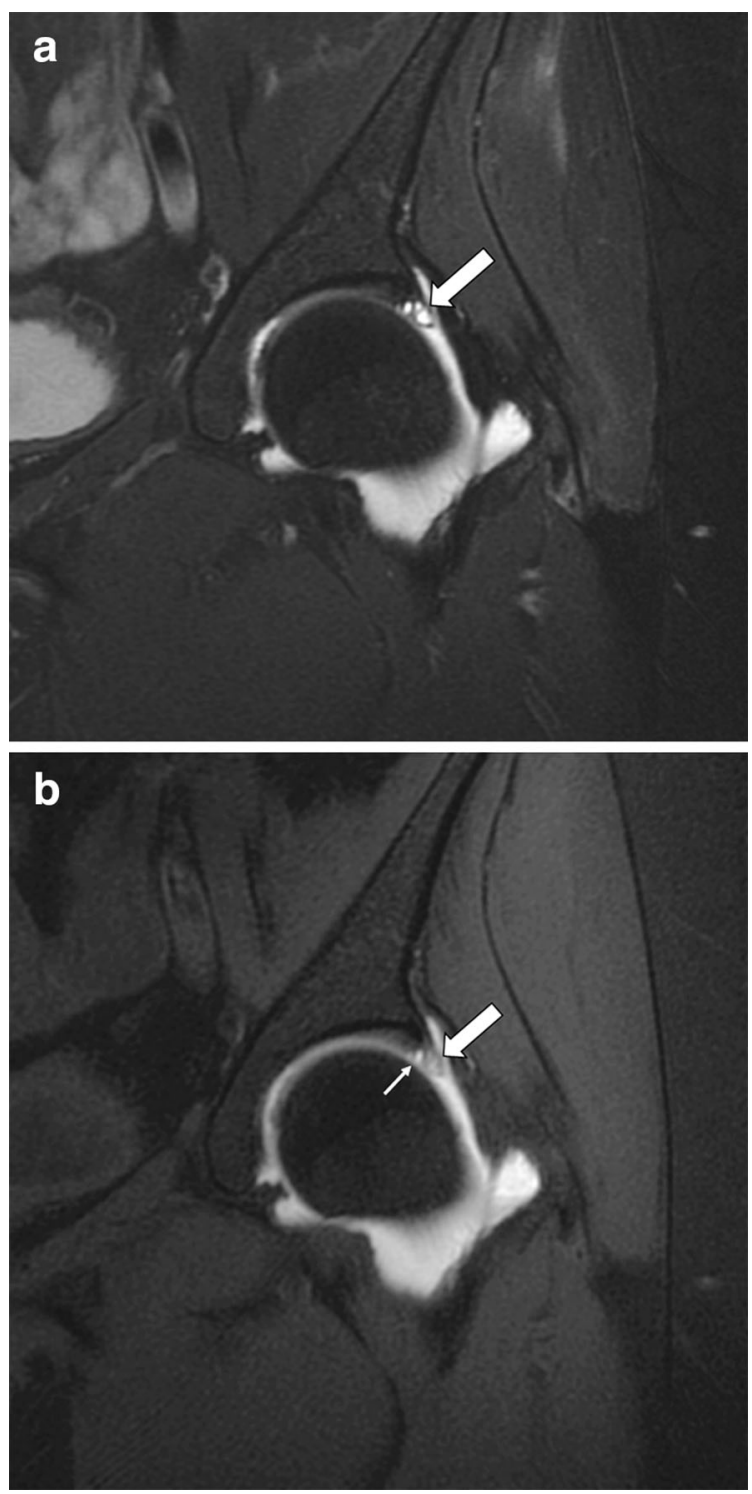

Fig. 11 A 36-year-old active female with 9 months of progressive anterior hip pain limiting her ability to work. a Coronal $\mathrm{T} 2$ fatsuppressed MR arthrogram image shows labral degeneration with intrasubstance cyst formation (thick arrow). b Corresponding coronal T1 fat-suppressed MR arthrogram image shows a labral tear (thin arrow) with imbibition of intra-articular contrast and generalized degeneration with intrasubstance cysts (better seen on T2 image) (thick arrow)

accuracy of non-contrast MR has undoubtedly improved substantially since then. Surgical and radiologic studies have both demonstrated an overwhelming prevalence of tears in the anterosuperior quadrant $[4,65,69,71]$, possibly due to the overall decreased tensile and compressive strength of this segment [67]. Imaging features of tears include contrast extending into the substance of the labrum (Figs. 10, 11, 12), most often from the articular surface; blunting or irregularity of the labral apex or undersurface; or complete detachment from the acetabulum (Fig. 10) [64,
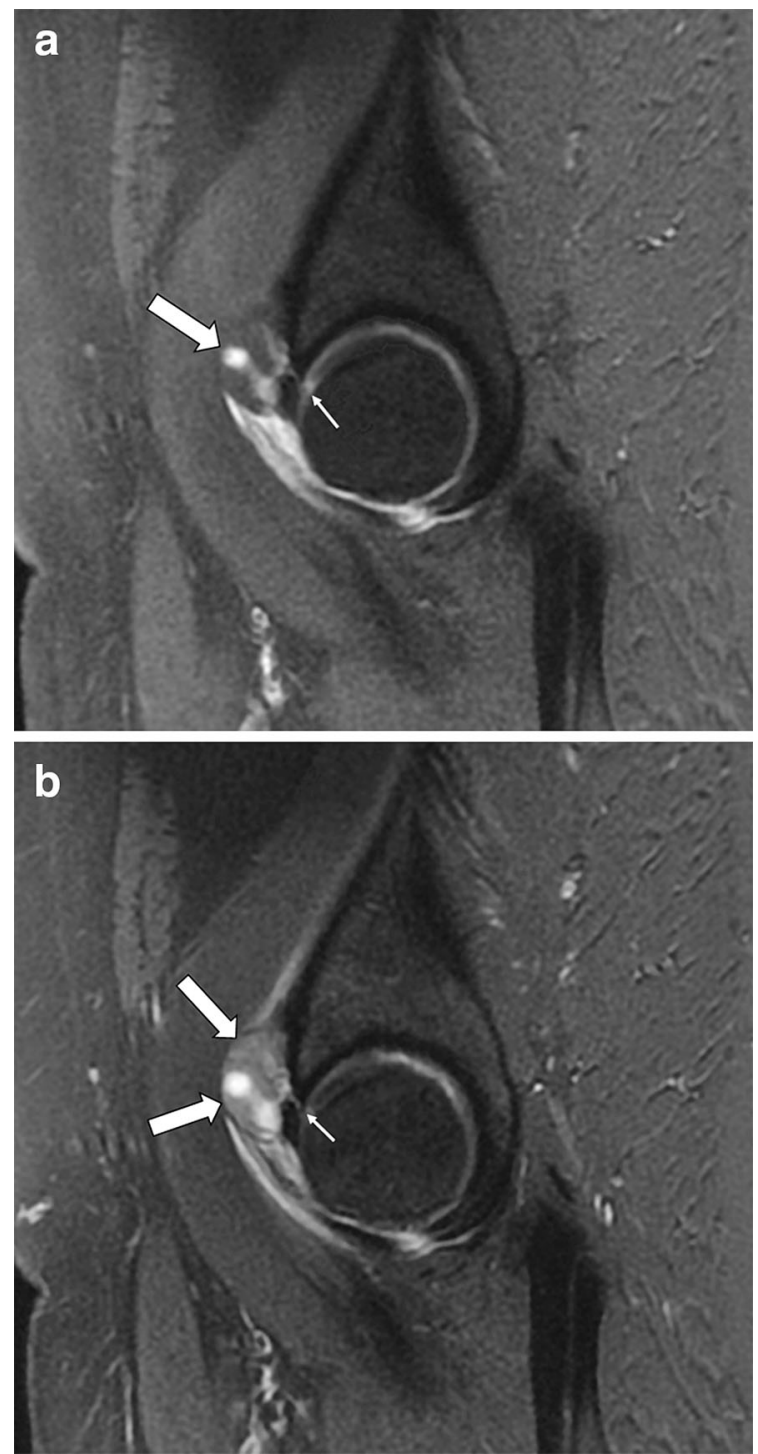

Fig. 12 A 48-year-old female with progressive anterior hip pain, worsened by sitting. a Sagittal T1 fat-suppressed MR arthrogram image shows a subtle but complete anterior labral tear (thin arrow) with intra-articular contrast extending into and partially filling a large anterior paralabral cyst (thick arrow). b Sagittal T2 fat-suppressed MR arthrogram image more clearly depicts the anterior paralabral cyst (thick arrows) and demonstrates the anterior labral tear (thin arrow)

66]. Secondary findings may be useful and include paralabral cysts (Fig. 12), which are most commonly on the capsular surface of the labrum, may extend into the subchondral bone of the acetabulum, and may or may not fill with gadolinium contrast [64]. Again, it is important to recognize the normal variant sublabral sulcus, which is more regular, shallower, and not associated with paralabral cysts. Although there are both established surgical and imaging labral tear type classification systems, these systems lack correlation as evidenced by Blankenbaker et al. [71]. Therefore, it is recommended to describe the tear 
position (quadrant), length, and chondrolabral junction involvement rather than specific tear type [71] (Fig. 11).

It is important to realize that the natural history of labral tears is unknown [8]. Not all tears are symptomatic, and some may heal spontaneously [8]. In athletes with persistent pain and imaging evidence of labral tear, arthroscopic management is the standard treatment (Fig. 10b, c) and has been proven effective with most athletes returning to sports within 3-8 months [8, 72]. Additionally, a 10-year follow-up study of arthroscopy in athletes by Byrd demonstrated $87 \%$ of patients with labral debridement return to sports and only concomitant osteoarthritis led to poor outcomes [73].

\section{Orthopedic Pearl}

In most cases, a labral tear is due to abnormal bony architecture (e.g., dysplasia, impingement) or hip instability. Thus, in essence, the labrum is an "innocent bystander," and recurrent tears will occur unless the underlying abnormalities (bony and capsular) are corrected.

\section{Chondral Injury}

Articular cartilage is a complex combination of water, collagen, and proteoglycans, which help to evenly distribute weight and forces, absorb pressure, and enable gliding of the bony structures of the joint. The layered nature of cartilage matrix contributes to its function and imaging appearance, including a narrow, horizontally oriented, and tightly packed hypointense superficial layer, followed by a larger, randomly arranged, mildly hyperintense transitional layer, and finally a water-poor, hypointense deep layer that attaches via calcified cartilage to the subchondral bone [74]. When significant, shearing forces and/or impaction may disrupt one or more of these layers, resulting in articular cartilage damage and susceptibility to progressive injury and degeneration.

Chondral injuries are commonly described in combination with other abnormalities, specifically in association with labral tears [22, 74-76], femoroacetabular impingement [4, 22, 31], and following subluxations and dislocations [31]. Therefore, the athletes who are predisposed to labral pathology, underlying FAI morphology, and subluxation or dislocation of the hip are also considered at risk for chondral injury.

Though many hip injuries result in characteristic symptoms, chondral injuries produce nonspecific hip or groin pain with possible radiation to the anterior thigh, similar to other intra-articular pathology [76]. Further, some chondral injuries may be asymptomatic because of the lack of chondral innervation [76], and noxious stimuli in chondral injuries are more likely due to associated abnormalities, such as labral tears, subchondral bone edema, and reactive synovitis.

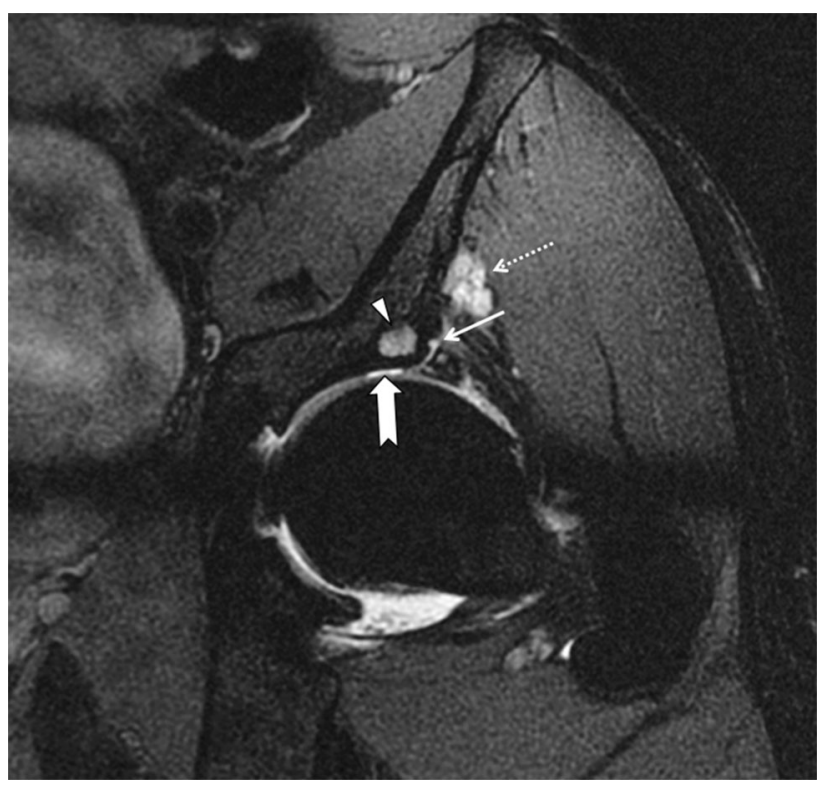

Fig. 13 A 32-year-old athletic male and former collegiate hockey player with 1 year of anterior hip pain and mixed FAI morphology (same patient as Fig. 8). Radial proton density fat-suppressed MR arthrogram image shows a focal full-thickness chondral defect of the anterosuperior acetabulum (notched arrow), which is filled with intraarticular contrast, and associated overlying subchondral cyst formation of the anterosuperior acetabulum (arrowhead). Additional findings include a complete anterosuperior labral tear (thin arrow), a degenerated labrum with increased intrasubstance signal and irregular morphology, and an adjacent paralabral cyst (dotted arrow)

Accordingly, the clinical diagnosis of chondral injury is challenging, and imaging is pivotal.

As with other intra-articular pathology, MR arthrography is recommended for the best possible evaluation of chondral pathology. Although relatively poor interobserver variability limited the study, Schmid et al. [75] exhibited up to $79 \%$ sensitivity and $77 \%$ specificity for detection of chondral pathology by MR arthrography. Imaging findings of abnormal cartilage depend on the injury and include the following: surface irregularity and loss of the superficial hypointense line, partial or full thickness cartilage defects filled with intra-articular contrast on MR arthrography (Fig. 13), and linear high signal extending into or under the cartilage consistent with fissures and flap tears [74]. Focal chondral abnormalities are most common in the anterosuperior acetabulum [74, 75] and likely explained by the association with labral tears and FAI morphology (Fig. 13). A focal cleft of the superior acetabulum at the 12 o'clock position may be seen in up to $10 \%$ of the population and is a normal variant supraacetabular fossa [74], which should not be confused with a focal chondral injury.

Though MR arthrography is the current imaging method of choice for cartilage assessment, it has its limitations [76], and several advanced imaging techniques, including T2 mapping and delayed gadolinium-enhanced MR 

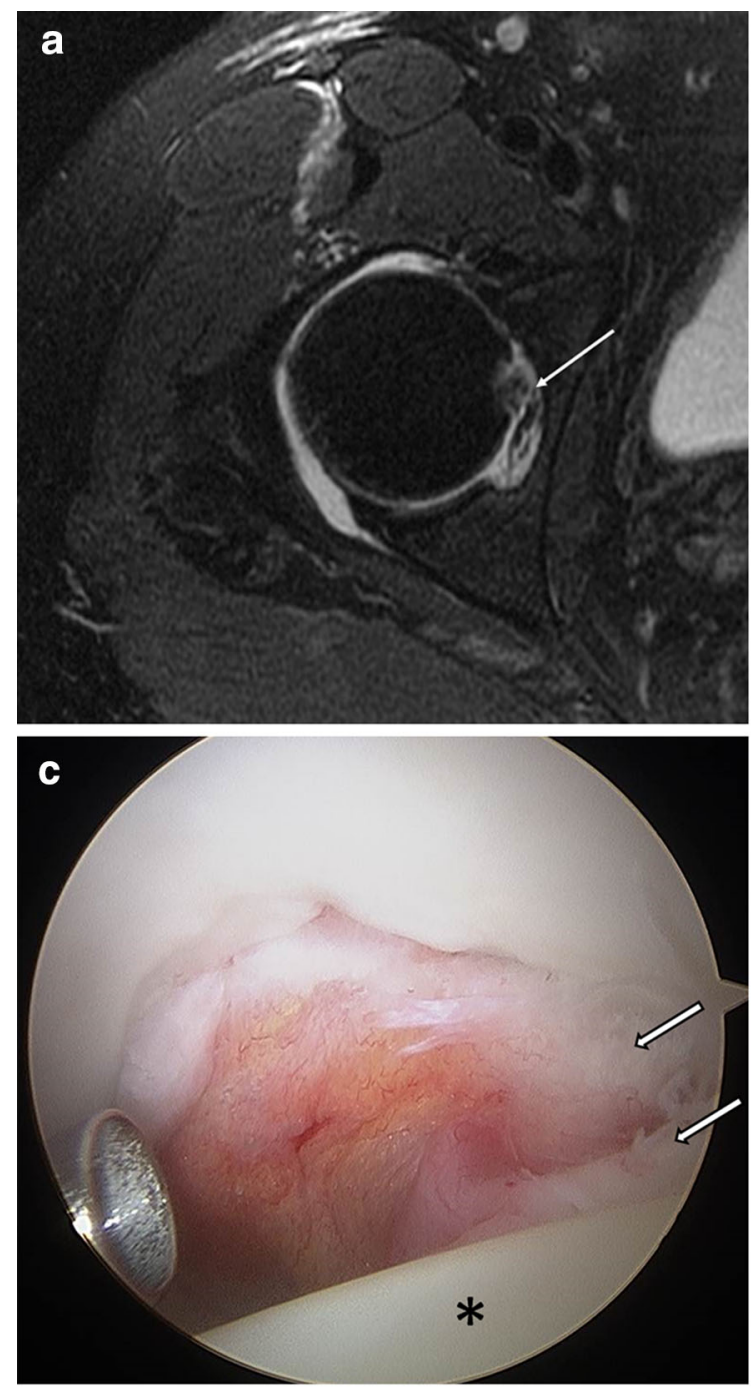

Fig. 14 a, b A 60-year-old female with progressive right hip pain, worsened by climbing, sitting, and twisting. a Axial T2 fat-suppressed MR arthrogram image exhibits irregular linear contrast extending into the substance of the ligamentum teres (arrow), consistent with an arthroscopically proven partial tear of the medial band of the ligamentum teres. b Coronal T2 fat-suppressed MR arthrogram image shows linear extension of contrast into the ligamentum teres (arrow).

imaging of cartilage (dGEMRIC), have gained much attention recently. Unfortunately, long acquisition times and lack of standardization are currently limiting the clinical applicability of these latter options. Thus, more routine cartilage sequences, including fat-suppressed 3D spoiled gradient echo, as well as standard proton density and $\mathrm{T} 2$ fast spin echo and radial images, remain the mainstays of cartilage evaluation.

The significance of chondral injuries lies in their limited ability to heal and the risk for progression to premature osteoarthritis. Thus, numerous surgical techniques for repair have been attempted and are being developed,
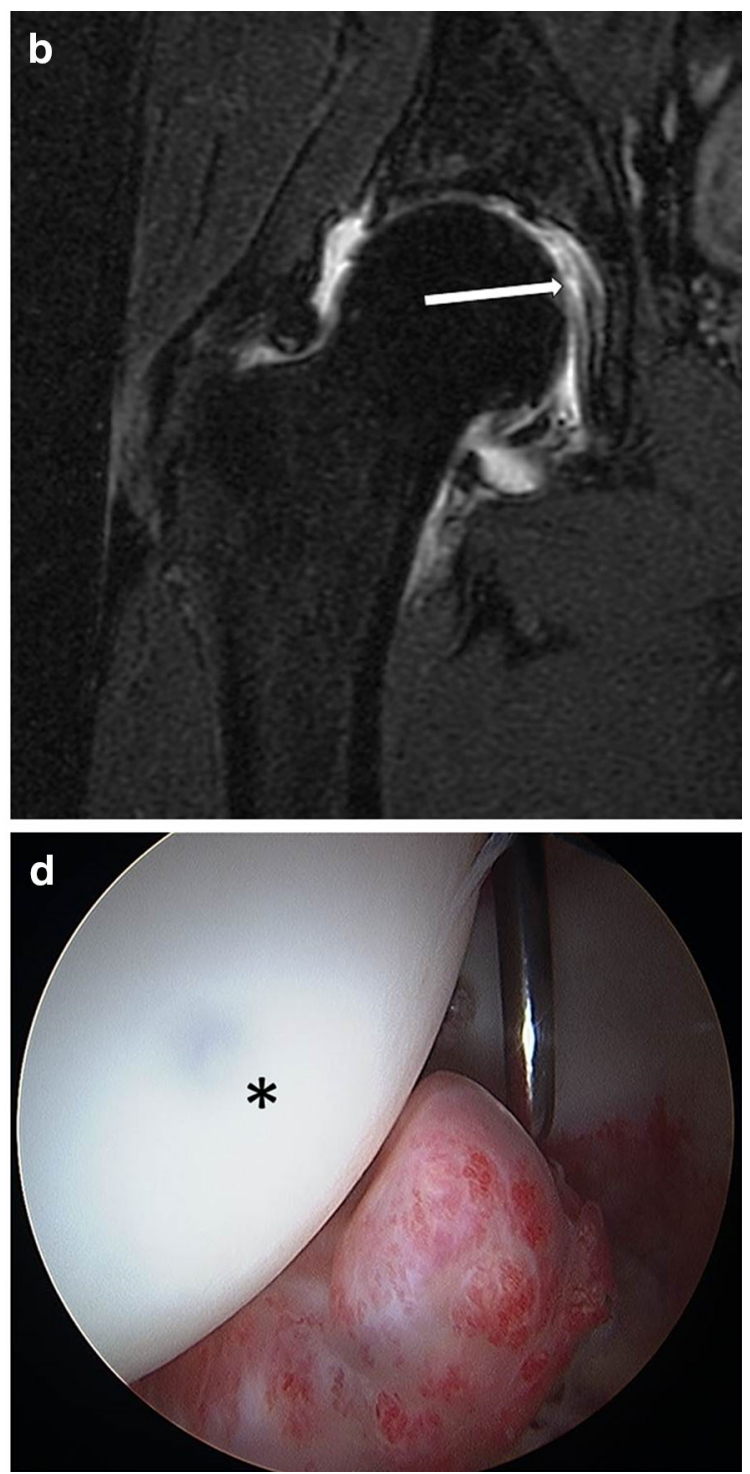

c Representative arthroscopic image of a different patient with a partially torn ligamentum teres (arrows indicate the ends of the tear) adjacent to the femoral head (asterisk). d Representative arthroscopic image of another patient with a chronic (rounded edges), complete tear of the ligamentum teres (at tip of metal probe) adjacent to the femoral head (asterisk)

including chondroplasty, osteochondral drilling, osteochondral auto- and allografts, autologous chondrocyte implantation (ACI), and, currently most common, microfracture [76]. Microfracture is most extensively studied in athletes and has demonstrated significant anatomic and functional improvement [77, 78].

\section{Orthopedic Pearl}

At arthroscopy, chondral damage is found in $33 \%$ of patients who had no articular cartilage abnormalities visualized on the preoperative MR arthrogram [75]. 


\section{Ligamentum Teres Tear}

The ligamentum teres (LT) is an intra-articular ligament, comprised of 2-3 bands, connecting the fovea capitis of the medial femoral head and the transverse ligament of the inferior acetabular notch [79•, 80]. This ligament plays little role in stabilization of the adult hip; however, it may transmit a branch artery to the femoral head in some adult patients. Despite the lack of known significance in adults, it is recognized as a potential source of pain if torn [41, 80, 81]. Not only is it cited as the third most common cause of hip pain identified in athletes undergoing arthroscopy [80], but nearly all $(96 \%)$ of the patients in one study who underwent debridement following traumatic LT tear experienced significant improvement in symptoms [81], including eight patients with isolated LT pathology.

The most commonly known etiology of ligamentum teres injury is trauma, ranging from dislocation to extreme abduction to relatively minor twisting or external rotation of the hip [79•, 80, 81]. Thus, sports with relatively high impact or twisting movements, including football, ice hockey, snow skiing, and dance, predispose athletes to LT injuries [79•, 81]. Symptoms are typically nonspecific, including deep anterior groin or hip pain, and often accompanied by mechanical snapping or catching sensations, which were identified in $83 \%$ of patients with surgically confirmed LT tears $[41,79 \bullet, 80,81]$.

Noninvasive diagnosis of LT tears is challenging, not only because of a lack of specific symptoms, but also because of poor visualization on imaging. LT tears have been found in 4-15\% of patients undergoing arthroscopy [80], but surgically confirmed tears on MR or MR arthrography imaging were diagnosed in only $42-67 \%$ of patients retrospectively reviewed in one study [79॰] and in only $8-11 \%$ of patients prospectively evaluated in additional studies [80, 81].

In these studies, the most important imaging clues to LT tears include high intrasubstance signal intensity (intraarticular contrast on $\mathrm{T} 1$ and $\mathrm{T} 2$ sequences), irregularity of the peripheral fibers (partial tears), and ligament discontinuity (complete tears) (Fig. 14) [79•, 80]. Even though there is limited accuracy, MR arthrography is still considered the best imaging method for diagnosis, and the oblique axial plane is best for its evaluation [80].

Surgical debridement of partially torn fibers or completely torn remnant stumps has produced excellent resolution of symptoms and is considered the most appropriate treatment for these athletes (Fig. 14c, d) [79•, 80, 81].

\section{Orthopedic Pearl}

A torn ligament teres is often found at arthroscopy in patients that have catching and locking of the hip, but no evidence of loose bodies or labral tears on preoperative imaging.

\section{Tendons and Muscles}

The soft tissues surrounding the hip dictate joint function and stability. Soft tissue injuries range from tendon avulsions or myotendinous tears to muscle strains and tendinopathy. Among all sports-related hip injuries, musculotendinous injuries are the most common $[3,4,82]$.

\section{Acute Injuries}

Muscle contusions and strains are important acute injuries to distinguish. Contusions result from direct blows and consequently are seen in contact sports such as football. Characteristically, edema is localized in the deep aspect of muscle, abutting the bone against which it was impacted [83]. Muscle strain, on the other hand, affects the muscle more diffusely, usually centered at or near the myotendinous junction. These injuries are graded by the presence of edema (grade I) and associated partial (grade II) or fullthickness (grade III) tears [23, 83]. T2-weighted images are most useful to identify edema, demonstrating feathery high T2 signal from interstitial fluid or hemorrhage, with preserved underlying muscle architecture. T1-weighted sequences are equally important to identify loss of tissue planes, determine exact muscle and/or intramuscular tendon involvement [84], and identify subacute hematomas (T1 bright) or fatty atrophy of chronic injury (decreased muscle bulk replaced with high $\mathrm{T} 1$ signal) $[23,82]$. The proximal hamstring (Fig. 15) [85, 86], specifically the biceps femoris [84], and proximal adductor musculotendinous units are the most susceptible to these injuries about the hip [7].

\section{Othorpedic Pearl}

Complete avulsions (tears) of the semimembranosus and conjoined tendon should immediately be referred for surgical repair. Late repairs and reconstructions are more difficult and often have less than optimal outcomes.

\section{Overuse Injuries}

Tendinopathy is a degenerative condition affecting athletes because of chronic overuse of a given tendon or musculotendinous unit. Symptom onset is usually insidious and includes pain, which is exacerbated by resisted function. In general, tendinopathy on MRI exhibits focal or diffuse tendon thickening with increased or intermediate $\mathrm{T} 2$ signal [85, 87-89]. Small, recurrent intrasubstance collagen fibril 


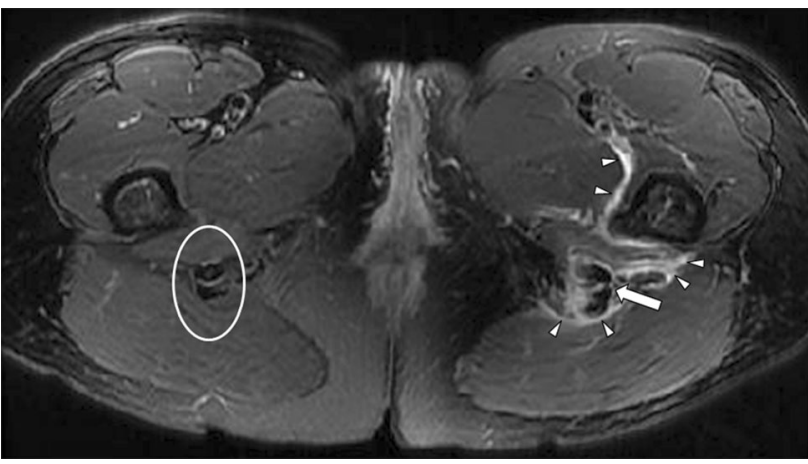

Fig. 15 A 51-year-old female runner with acute fall and pain. Axial T2 fat-suppressed image shows irregularity and partial tearing of the proximal left hamstring myotendinous unit (thick arrow) with moderate surrounding high T2 signal throughout the deep fascial planes (arrowheads) from edema and hematoma, consistent with a grade II myotendinous strain. Note the normal configuration of the proximal right hamstring tendons (oval)

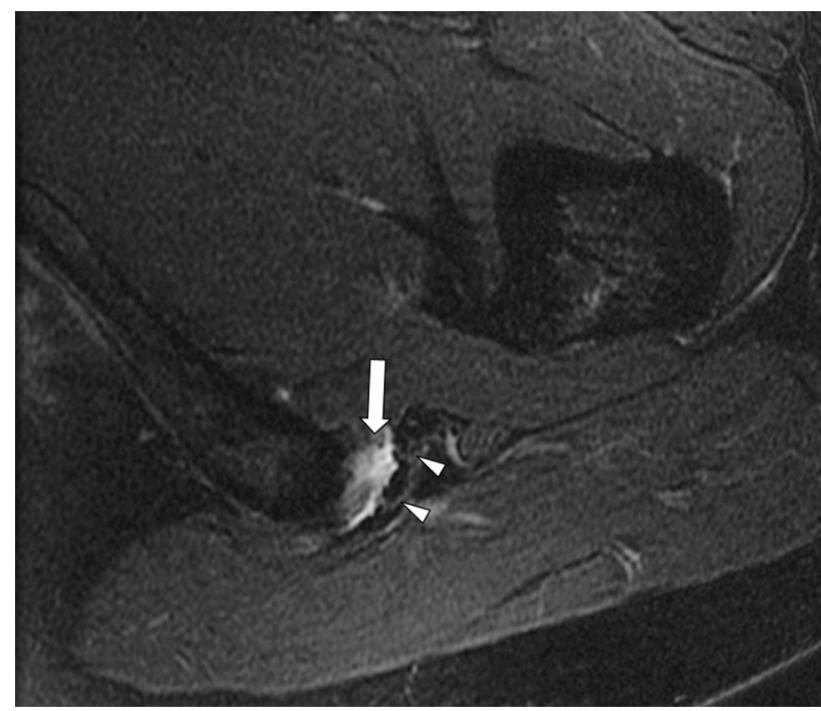

Fig. 16 A 50-year-old female aerobics instructor with pain, greatest with hip flexion and crossing the body during stretching. Axial T2 image reveals a partial tear of the proximal hamstring origin, including irregularity of the proximal hamstring tendon (arrowheads) and T2 hyperintensity (fluid) (arrow) between the proximal hamstring tendon and ischial tuberosity

tears may contribute to chronic tendinopathy, occasionally seen on imaging as focal linear high T2 intrasubstance signal without superimposed acute injury [87]. Partial thickness tears (Figs. 16, 17) demonstrate focal discontinuity and high T2 signal, and full-thickness tears are easily identified as a wavy hypointense tendon, fluid-filled gap at the tear site, and possible tendon retraction [82]. Tendons most commonly affected by chronic tendinopathy include the proximal hamstrings (Fig. 16) [85, 88], distal abductors (Fig. 17) [90], proximal tensor fascia lata (Fig. 18) [91], and proximal iliotibial band (Fig. 19) [92•].
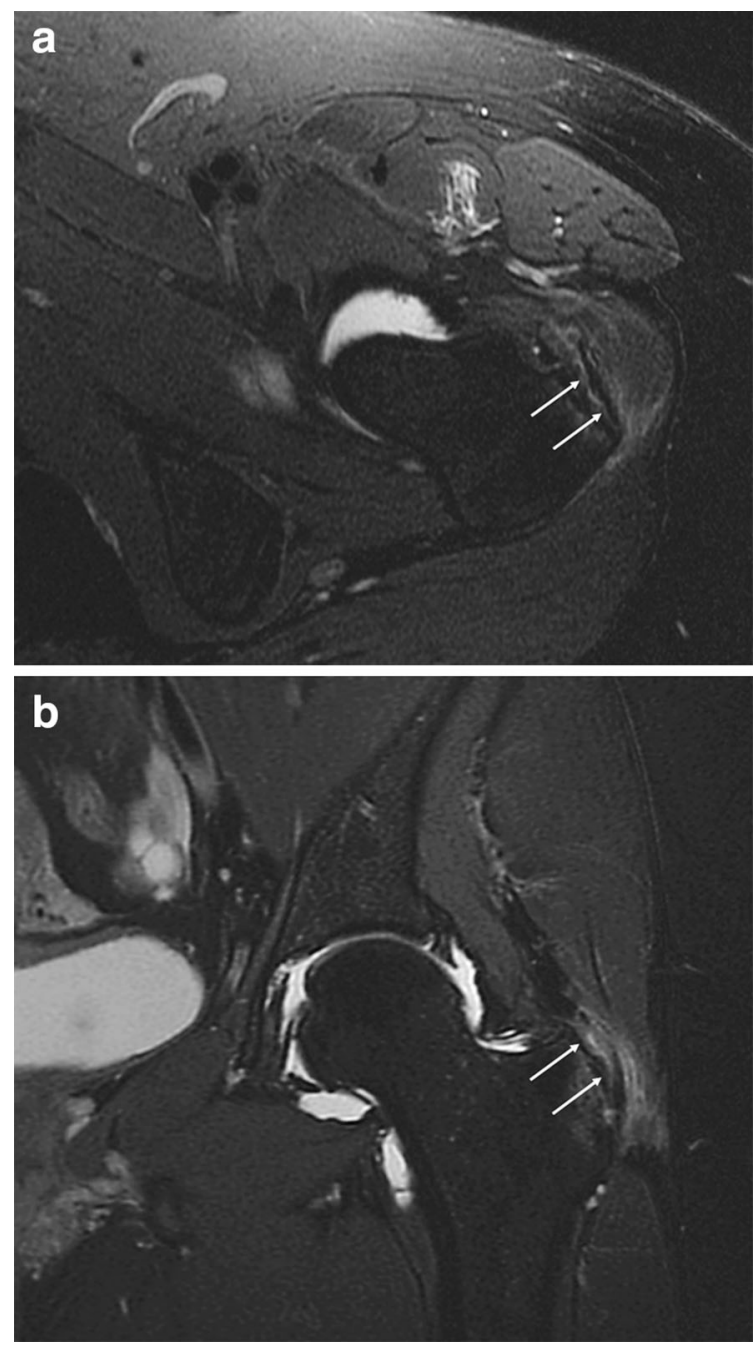

Fig. 17 A 36-year-old active female with progressive lateral hip pain. a Axial T2 fat-suppressed MR arthrogram image shows partial discontinuity and insinuating high T2 signal (fluid) (arrows) at the insertion of the gluteus minimis at the anterior facet of the greater trochanter, consistent with a partial tear. b Coronal T2 fat-suppressed MR arthrogram image confirm these findings

\section{Orthopedic Pearl}

Chronic hamstring tendinopathy may be associated with sciatic nerve symptoms and proximal hamstring tenotomies, in combination with sciatic nerve neurolyses, are often successful in alleviating chronic pain in these patients.

\section{Snapping Hip}

Another source of hip pain receiving attention in athletes recently is the snapping hip. There are three categories of snapping hip: intra-articular, internal, and external. Intraarticular snapping is caused by mobile intra-articular structures, including joint bodies, synovial osteochondromatosis, 


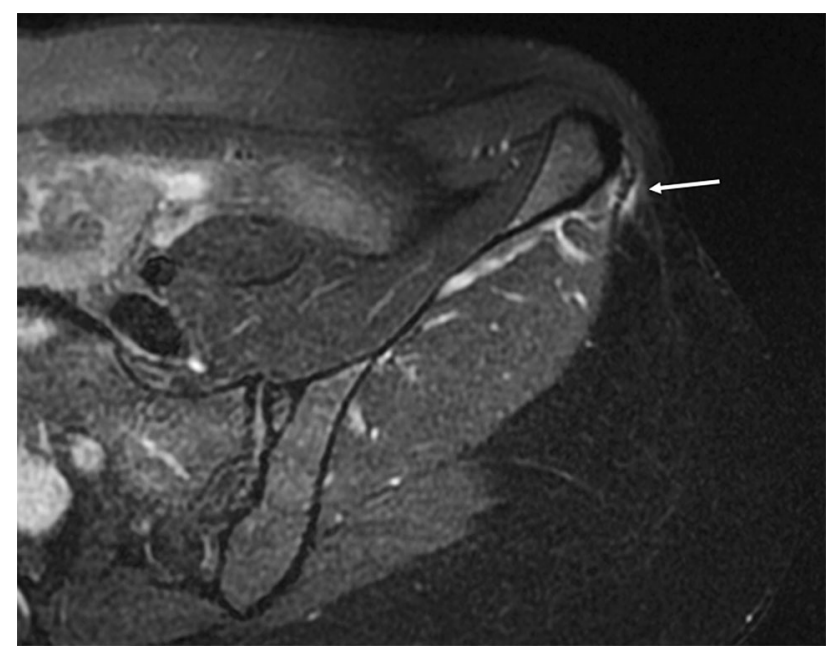

Fig. 18 A 40-year-old female runner with a history of tibial stress fractures who now presents with new lateral left hip pain. Axial T2 fat-suppressed image exhibits mild thickening of the proximal tensor fascia lata and surrounding high T2 signal near its origin from the anterior iliac crest (arrow), consistent with tensor fascia lata tendinopathy

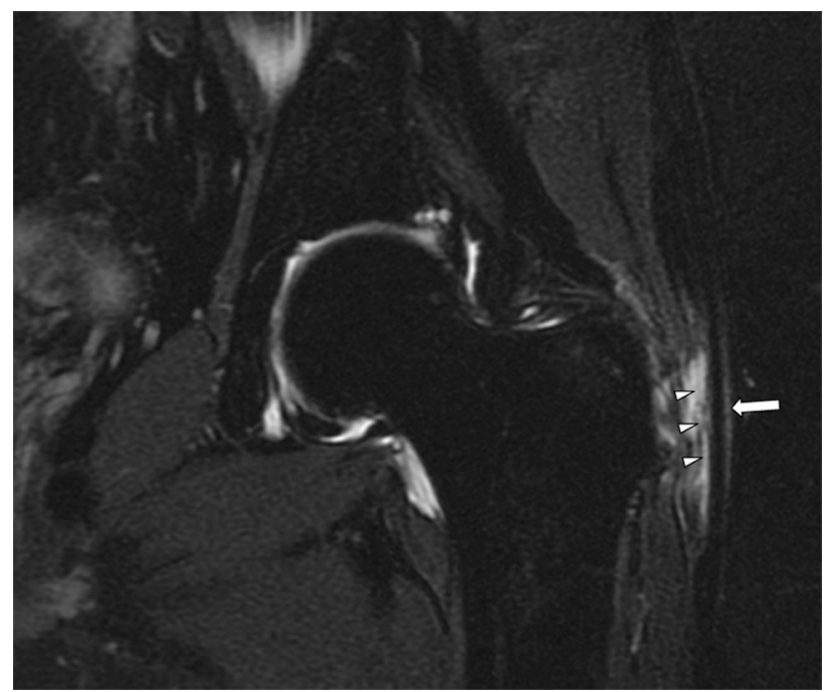

Fig. 19 A 61-year-old active female with increasing lateral posterior hip pain. Coronal T2 fat-suppressed MR arthrogram image demonstrates mild thickening of the proximal iliotibial band (arrow) as it courses over the greater trochanter and underlying fluid signal (arrowheads), representing proximal iliotibial band syndrome and bursitis

or labral fragments [41, 82]. Internal and external snappings are caused by abnormal tendon movement, including the iliopsoas tendon in internal snapping and tensor fascia lata and/or gluteal tendons in external snapping.

Iliopsoas snapping has received attention in recent orthopedic literature because of positive clinical outcomes of arthroscopic release techniques [93-95]. The iliopsoas tendon may snap over the iliopectineal eminence, at the lesser trochanter, or between the iliacus muscle and iliac wing $[22,93,96,97]$, resulting in a palpable or audible snap that may be elicited with movement from the frog-leg position (flexed, abducted, and externally rotated hip) to an extended, internally rotated position $[22,41]$. Athletes who perform movements of rotation while in hip flexion, such as dancers, gymnasts, and martial artists, are at greatest risk $[3,96,97]$ and often present with pain, decreased range of motion, and, in many, local inguinal swelling [98]. Because snapping hip is a dynamic condition, ultrasound is considered the best imaging method for diagnosis [22, 41, 99], allowing visualization of abrupt motion of the tendon during maneuvers and assessment of bursal fluid and tendinopathy. However, snapping of the tendon often cannot be documented with ultrasound because of the position that the patient must be in to make the tendon snap. MRI may help in difficult cases, demonstrating a subluxated or displaced psoas tendon, tendon thickening anterior to the hip joint, and associated iliopsoas bursal fluid [98], as well as increased T2 signal around the musculotendinous junction [97]. MRI also may identify those patients with snapping hips due to ischiofemoral impingement. Conservative management is preferred [41, 97], though athletes with continued pain may proceed to ultrasound-guided injection and/or surgical intervention (iliopsoas tenotomy), with nearly all athletes returning to play following surgery [9395].

\section{Conclusion}

Due to the complexity of the hip joint, there are a large number of structures that may be injured and cause hip pain in athletes. The wide variety of complex motions required by different sports result in a broad array of osseous injuries, impingement conditions, intra-articular pathology, and myotendinous injury, leading to varied presentations. Many of these injuries lead to prolonged time away from sports. Thus, recognition of these varied hip pathologies is vital to prompt diagnosis and appropriate treatment, providing the athlete the best chance to return to sports and avoid lasting consequences.

\section{Compliance with Ethics Guidelines}

Conflict of Interest LM Ladd, DG Blankenbaker, KM Davis, and JS Keene declare no conflicts of interest.

Human and Animal Rights and Informed Consent All studies by the authors involving animal and/or human subjects were performed after approval by the appropriate institutional review boards. When required, written informed consent was obtained from all participants. 


\section{References}

Papers of particular interest, published recently, have been highlighted as:

- Of importance

-• Of major importance

1. Cibulka MT, White DM, Woehrle J, Harris-Hayes M, Enseki K, Fagerson TL, et al. Hip pain and mobility deficits-hip osteoarthritis: clinical practice guidelines linked to the international classification of functioning, disability, and health from the orthopaedic section of the American Physical Therapy Association. J Orthop Sports Phys Ther. 2009;39(4):A1-25.

2. Winter DA. Human balance and posture control during standing and walking. Gait \& Posture. 1995;3(4):193-214.

3. Boyd KT, Peirce NS, Batt ME. Common hip injuries in sport. Sports Med. 1997;24(4):273-88.

4. Feeley BT, Powell JW, Muller MS, Barnes RP, Warren RF, Kelly BT. Hip injuries and labral tears in the national football league. Am J Sports Med. 2008;36(11):2187-95.

5. Koulouris G. Imaging review of groin pain in elite athletes: an anatomic approach to imaging findings. Am J Roentgenol. 2008;191(4):962-72.

6. Quinn A. Hip and Groin Pain: Physiotherapy and Rehabilitation Issues. Open Sports Med J. 2010;4:93-107.

7. Hölmich P. Long-standing groin pain in sportspeople falls into three primary patterns, a "clinical entity" approach: a prospective study of 207 patients. Br J Sports Med. 2007;41(4):247-52.

8. Narvani AA, Tsiridis E, Kendall S, Chaudhuri R, Thomas P. A preliminary report on prevalence of acetabular labrum tears in sports patients with groin pain. Knee Surg Sports Traumatol Arthrosc. 2003;11(6):403-8.

9. Taljanovic MS, Daffner RH, Weissman BN, Appel M, Arnold E, Bancroft LW et al. ACR Appropriateness Criteria ${ }^{\circledR}$ Chronic hip pain. Reston: American College of Radiology (ACR); 2011.

10. Yoon LS, Palmer WE, Kassarjian A. Evaluation of radialsequence imaging in detecting acetabular labral tears at hip MR arthrography. Skelet Radiol. 2007;36(11):1029-33.

11. Rakhra KS, Sheikh AM, Allen D, Beaulé PE. Comparison of MRI alpha angle measurement planes in femoroacetabular impingement. Clin Orthop Relat Res. 2009;467(3):660-5.

12. Lecouvet FE, Vande Berg BC, Malghem J, Lebon CJ, Moysan P, Jamart J, et al. MR imaging of the acetabular labrum: variations in 200 asymptomatic hips. Am J Roentgenol. 1996;167(4):1025-8.

13. Anderson K, Strickland SM, Warren R. Hip and groin injuries in athletes. Am J Sports Med. 2001;29(4):521-33.

14. Deangelis JP, Spindler KP. Traumatic bone bruises in the athlete's knee. Sports Health. 2010;2(5):398-402.

15. Blankenbaker DG, De Smet AA, Vanderby R, McCabe RP, Koplin SA. MRI of acute bone bruises: timing of the appearance of findings in a swine model. Am J Roentgenol. 2008;190(1):W1-7.

16. Bretlau T, Tuxøe J, Larsen L, Jørgensen U, Thomsen HS, Lausten GS. Bone bruise in the acutely injured knee. Knee Surg Sports Traumatol Arthrosc. 2002;10(2):96-101.

17. Berger FH, de Jonge MC, Maas M. Stress fractures in the lower extremity. The importance of increasing awareness amongst radiologists. Eur J Radiol. 2007;62(1):16-26.

18. Kaeding CC, Yu JR, Wright R, Amendola A, Spindler KP. Management and return to play of stress fractures. Clin J Sport Med. 2005;15(6):442-7.

19. Clough TM. Femoral neck stress fracture: the importance of clinical suspicion and early review. Br J Sports Med. 2002; 36(4):308-9.
20. Johansson C, Ekenman I, Törnkvist H, Eriksson E. Stress fractures of the femoral neck in athletes. The consequence of a delay in diagnosis. Am J Sports Med. 1990;18(5):524-8.

21. Niva MH, Kiuru MJ, Haataja R, Pihlajamäki HK. Fatigue injuries of the femur. J Bone Joint Surg Br. 2005;87(10):1385-90.

22. Blankenbaker DG, De Smet AA. Hip injuries in athletes. Radiol Clin North Am. 2010;48(6):1155-78.

23. Newman JS, Newberg AH. MRI of the painful hip in athletes. Clin Sports Med. 2006;25(4):613-33.

24. Slocum KA, Gorman JD, Puckett ML, Jones SB. Resolution of abnormal MR signal intensity in patients with stress fractures of the femoral neck. Am J Roentgenol. 1997;168(5):1295-9.

25. Keene JS, Lash EG. Negative bone scan in a femoral neck stress fracture. A case report. Am J Sports Med. 1992;20(2):234-6.

26. Pallia CS, Scott RE, Chao DJ. Traumatic hip dislocation in athletes. Curr Sports Med Rep. 2002;1(6):338-45.

27. Shindle MK, Ranawat AS, Kelly BT. Diagnosis and management of traumatic and atraumatic hip instability in the athletic patient. Clin Sports Med. 2006;25(2):309-26.

28. Giza E, Mithöfer K, Matthews H, Vrahas M. Hip fracture-dislocation in football: a report of two cases and review of the literature. Br J Sports Med. 2004;38(4):E17.

29. Brooks RA, Ribbans WJ. Diagnosis and imaging studies of traumatic hip dislocations in the adult. Clin Orthop Relat Res. 2000;377:15-23.

30. Laorr A, Greenspan A, Anderson MW, Moehring HD, McKinley T. Traumatic hip dislocation: early MRI findings. Skelet Radiol. 1995;24(4):239-45.

31. Philippon MJ, Kuppersmith DA, Wolff AB, Briggs KK. Arthroscopic findings following traumatic hip dislocation in 14 professional athletes. Arthroscopy. 2009;25(2):169-74.

32. Moorman CT, Warren RF, Hershman EB, Crowe JF, Potter HG, Barnes R, et al. Traumatic posterior hip subluxation in American football. J Bone Joint Surg Am. 2003;85-A(7):1190-6.

33. Flanigan DC, De Smet AA, Graf B. Magnetic resonance imaging in traumatic hip subluxation. Indian J Orthop. 2011;45(3):272-5.

34. Berkes MB, Cross MB, Shindle MK, Bedi A, Kelly BT. Traumatic posterior hip instability and femoroacetabular impingement in athletes. Am J Orthop (Belle Mead NJ). 2012;41(4):166-71.

35. Poggi JJ, Callaghan JJ, Spritzer CE, Roark T, Goldner RD. Changes on magnetic resonance images after traumatic hip dislocation. Clin Orthop Relat Res. 1995;319:249-59.

36. Nepple JJ, Brophy RH, Matava MJ, Wright RW, Clohisy JC. Radiographic findings of femoroacetabular impingement in National Football League combine athletes undergoing radiographs for previous hip or groin pain. Arthroscopy. 2012;28(10):1396-403.

37. Philippon M, Schenker M, Briggs K, Kuppersmith D. Femoroacetabular impingement in 45 professional athletes: associated pathologies and return to sport following arthroscopic decompression. Knee Surg Sports Traumatol Arthrosc. 2007;15(7):908-14.

38. - Byrd JW, Jones KS. Arthroscopic management of femoroacetabular impingement in athletes. Am J Sports Med. 2011;39 (Suppl):7S-13S. The first long-term (2-year follow-up) outcome study of surgical management of FAI in athletes showed good surgical outcomes and excellent return to play.

39. Ganz R, Parvizi J, Beck M, Leunig M, Nötzli H, Siebenrock KA. Femoroacetabular impingement: a cause for osteoarthritis of the hip. Clin Orthop Relat Res. 2003;417:112-20.

40. Byrd JWT. Femoroacetabular Impingement in athletes: current concepts. Am J Sports Med. 2013;42(3):737-51.

41. Tibor LM, Sekiya JK. Differential diagnosis of pain around the hip joint. Arthroscopy. 2008;24(12):1407-21.

42. Tannast M, Siebenrock KA, Anderson SE. Femoroacetabular impingement: radiographic diagnosis-what the radiologist should know. Am J Roentgenol. 2007;188(6):1540-52. 
43. Beck M, Kalhor M, Leunig M, Ganz R. Hip morphology influences the pattern of damage to the acetabular cartilage: femoroacetabular impingement as a cause of early osteoarthritis of the hip. J Bone Joint Surg Br. 2005;87(7):1012-8.

44. Brian P, Bernard S, Flemming D. Femoroacetabular impingement: screening and definitive imaging. Semin Roentgenol. 2010; 45(4):228-37.

45. Pfirrmann CW, Mengiardi B, Dora C, Kalberer F, Zanetti M, Hodler J. Cam and pincer femoroacetabular impingement: characteristic MR arthrographic findings in 50 patients. Radiology. 2006;240(3):778-85.

46. Kassarjian A, Yoon LS, Belzile E, Connolly SA, Millis MB, Palmer WE. Triad of MR arthrographic findings in patients with cam-type femoroacetabular impingement. Radiology. 2005;236(2):588-92.

47. Lohan DG, Seeger LL, Motamedi K, Hame S, Sayre J. Cam-type femoral-acetabular impingement: is the alpha angle the best MR arthrography has to offer? Skelet Radiol. 2009;38(9):855-62.

48. Larson CM, Sikka RS, Sardelli MC, Byrd JW, Kelly BT, Jain RK, et al. Increasing alpha angle is predictive of athletic-related "hip" and "groin" pain in collegiate National Football League prospects. Arthroscopy. 2013;29(3):405-10.

49. James SL, Ali K, Malara F, Young D, O’Donnell J, Connell DA. MRI findings of femoroacetabular impingement. Am J Roentgenol. 2006;187(6):1412-9.

50. Boykin RE, Patterson D, Briggs KK, Dee A, Philippon MJ. Results of arthroscopic labral reconstruction of the hip in elite athletes. Am J Sports Med. 2013;41(10):2296-301.

51. Gerhardt MB, Romero AA, Silvers HJ, Harris DJ, Watanabe D, Mandelbaum BR. The prevalence of radiographic hip abnormalities in elite soccer players. Am J Sports Med. 2012;40(3): $584-8$.

52. - Sutter R, Dietrich TJ, Zingg PO, Pfirrmann CW. Femoral antetorsion: comparing asymptomatic volunteers and patients with femoroacetabular impingement. Radiology. 2012;263(2):475-83. Demonstrates the feasibility and benefits (no ionizing radiation) of utilizing MRI to measure femoral antetorsion. Secondarily reiterates the importance of femoral antetorsion as a cause of impingement symptoms in patients without FAI morphology.

53. - Sutter R, Pfirrmann CW. Atypical hip impingement. Am J Roentgenol. 2013;201(3):W437-42. An important up-to-date review of a less common but important form of impingement outside of FAI, highlighting the most recent literature.

54. Audenaert EA, Peeters I, Vigneron L, Baelde N, Pattyn C. Hip morphological characteristics and range of internal rotation in femoroacetabular impingement. Am J Sports Med. 2012;40(6): 1329-36.

55. Huber H, Haefeli M, Dierauer S, Ramseier LE. Treatment of reduced femoral antetorsion by subtrochanteric rotational osteotomy. Acta Orthop Belg. 2009;75(4):490-6.

56. Schneider B, Laubenberger J, Jemlich S, Groene K, Weber HM, Langer M. Measurement of femoral antetorsion and tibial torsion by magnetic resonance imaging. Br J Radiol. 1997;70(834):575-9.

57. Tomczak RJ, Guenther KP, Rieber A, Mergo P, Ros PR, Brambs HJ. MR imaging measurement of the femoral antetorsional angle as a new technique: comparison with $\mathrm{CT}$ in children and adults. Am J Roentgenol. 1997;168(3):791-4.

58. Pan H, Kawanabe K, Akiyama H, Goto K, Onishi E, Nakamura T. Operative treatment of hip impingement caused by hypertrophy of the anterior inferior iliac spine. J Bone Joint Surg Br. 2008;90(5):677-9.

59. Larson CM, Kelly BT, Stone RM. Making a case for anterior inferior iliac spine/subspine hip impingement: three representative case reports and proposed concept. Arthroscopy. 2011;27(12): $1732-7$

60. • Hetsroni I, Poultsides L, Bedi A, Larson CM, Kelly BT. Anterior inferior iliac spine morphology correlates with hip range of motion: a classification system and dynamic model. Clin Orthop Relat Res. 2013;471(8):2497-503. The hallmark study to establish a classification system for AIIS morphology and correlate these morphologies to functional limitations and possible surgical candidacy.

61. Blankenbaker DG, Tuite MJ. Non-femoroacetabular impingement. Semin Musculoskelet Radiol. 2013;17(3):279-85.

62. Hetsroni I, Larson CM, Dela Torre K, Zbeda RM, Magennis E, Kelly BT. Anterior inferior iliac spine deformity as an extraarticular source for hip impingement: a series of 10 patients treated with arthroscopic decompression. Arthroscopy. 2012;28(11): 1644-53.

63. Hapa O, Bedi A, Gursan O, Akar MS, Güvencer M, Havitçioğlu $\mathrm{H}$, et al. Anatomic footprint of the direct head of the rectus femoris origin: cadaveric study and clinical series of hips after arthroscopic anterior inferior iliac spine/subspine decompression. Arthroscopy. 2013;29(12):1932-40.

64. Thomas JD, Li Z, Agur AM, Robinson P. Imaging of the acetabular labrum. Semin Musculoskelet Radiol. 2013;17(3):248-57.

65. Abe I, Harada Y, Oinuma K, Kamikawa K, Kitahara H, Morita F, et al. Acetabular labrum: abnormal findings at MR imaging in asymptomatic hips. Radiology. 2000;216(2):576-81.

66. Schmerl M, Pollard H, Hoskins W. Labral injuries of the hip: a review of diagnosis and management. J Manipulative Physiol Ther. 2005;28(8):632.

67. Smith CD, Masouros S, Hill AM, Amis AA, Bull AM. A biomechanical basis for tears of the human acetabular labrum. Br J Sports Med. 2009;43(8):574-8.

68. Wenger DE, Kendell KR, Miner MR, Trousdale RT. Acetabular labral tears rarely occur in the absence of bony abnormalities. Clin Orthop Relat Res. 2004;426:145-50.

69. Boykin RE, McFeely ED, Ackerman KE, Yen YM, Nasreddine A, Kocher MS. Labral injuries of the hip in rowers. Clin Orthop Relat Res. 2013;471(8):2517-22.

70. Czerny C, Hofmann S, Neuhold A, Tschauner C, Engel A, Recht MP, et al. Lesions of the acetabular labrum: accuracy of MR imaging and MR arthrography in detection and staging. Radiology. 1996;200(1):225-30.

71. Blankenbaker DG, De Smet AA, Keene JS, Fine JP. Classification and localization of acetabular labral tears. Skelet Radiol. 2007;36(5):391-7.

72. Philippon MJ, Weiss DR, Kuppersmith DA, Briggs KK, Hay CJ. Arthroscopic labral repair and treatment of femoroacetabular impingement in professional hockey players. Am J Sports Med. 2010;38(1):99-104.

73. Byrd JW, Jones KS. Hip arthroscopy in athletes: 10-year followup. Am J Sports Med. 2009;37(11):2140-3.

74. Petchprapa CN, Recht MP. Imaging of chondral lesions including femoroacetabular impingement. Semin Musculoskelet Radiol. 2013;17(3):258-71.

75. Schmid MR, Nötzli HP, Zanetti M, Wyss TF, Hodler J. Cartilage lesions in the hip: diagnostic effectiveness of MR arthrography. Radiology. 2003;226(2):382-6.

76. Yen YM, Kocher MS. Chondral lesions of the hip: microfracture and chondroplasty. Sports Med Arthrosc. 2010;18(2):83-9.

77. Byrd JW, Jones KS. Osteoarthritis caused by an inverted acetabular labrum: radiographic diagnosis and arthroscopic treatment. Arthroscopy. 2002;18(7):741-7.

78. Philippon MJ, Schenker ML, Briggs KK, Maxwell RB. Can microfracture produce repair tissue in acetabular chondral defects? Arthroscopy. 2008;24(1):46-50.

79. • Blankenbaker DG, De Smet AA, Keene JS, Del Rio AM. Imaging appearance of the normal and partially torn ligamentum teres on hip MR arthrography. Am J Roentgenol. 2012;199(5):1093-8. The first study to evaluate distinction and imaging characteristics of partial ligamentum teres tears on MR arthrogram. 
80. Bardakos NV, Villar RN. The ligamentum teres of the adult hip. J Bone Joint Surg Br. 2009;91(1):8-15.

81. Byrd JW, Jones KS. Traumatic rupture of the ligamentum teres as a source of hip pain. Arthroscopy. 2004;20(4):385-91.

82. Bencardino JT, Kassarjian A, Palmer WE. Magnetic resonance imaging of the hip: sports-related injuries. Top Magn Reson Imaging. 2003;14(2):145-60.

83. McMahon CJ, Wu JS, Eisenberg RL. Muscle edema. Am J Roentgenol. 2010;194(4):W284-92.

84. De Smet AA, Best TM. MR imaging of the distribution and location of acute hamstring injuries in athletes. Am J Roentgenol. 2000;174(2):393-9.

85. Davis KW. Imaging of the hamstrings. Semin Musculoskelet Radiol. 2008;12(1):28-41.

86. Kavanagh EC, Koulouris G, Ford S, McMahon P, Johnson C, Eustace SJ. MR imaging of groin pain in the athlete. Semin Musculoskelet Radiol. 2006;10(3):197-207.

87. Hodgson RJ, O'Connor PJ, Grainger AJ. Tendon and ligament imaging. Br J Radiol. 1016;2012(85):1157-72.

88. Zissen MH, Wallace G, Stevens KJ, Fredericson M, Beaulieu CF. High hamstring tendinopathy: mRI and ultrasound imaging and therapeutic efficacy of percutaneous corticosteroid injection. Am J Roentgenol. 2010;195(4):993-8.

89. Kingzett-Taylor A, Tirman PF, Feller J, McGann W, Prieto V, Wischer $\mathrm{T}$, et al. Tendinosis and tears of gluteus medius and minimus muscles as a cause of hip pain: MR imaging findings. Am J Roentgenol. 1999;173(4):1123-6.

90. Blankenbaker DG, Ullrick SR, Davis KW, De Smet AA, Haaland $\mathrm{B}$, Fine JP. Correlation of MRI findings with clinical findings of trochanteric pain syndrome. Skelet Radiol. 2008;37(10):903-9.
91. Bass CJ, Connell DA. Sonographic findings of tensor fascia lata tendinopathy: another cause of anterior groin pain. Skelet Radiol. 2002;31(3):143-8.

92. - Sher I, Umans H, Downie SA, Tobin K, Arora R, Olson TR. Proximal iliotibial band syndrome: what is it and where is it? Skeletal Radiol. 2011;40(12):1553-6. The first study to evaluate and describe the imaging appearance of unique strain injuries of the proximal iliotibial band.

93. Anderson SA, Keene JS. Results of arthroscopic iliopsoas tendon release in competitive and recreational athletes. Am J Sports Med. 2008;36(12):2363-71.

94. Jacobson T, Allen WC. Surgical correction of the snapping iliopsoas tendon. Am J Sports Med. 1990;18(5):470-4.

95. Hoskins JS, Burd TA, Allen WC. Surgical correction of internal coxa saltans: a 20-year consecutive study. Am J Sports Med. 2004;32(4):998-1001.

96. Lee KS, Rosas HG, Phancao JP. Snapping hip: imaging and treatment. Semin Musculoskelet Radiol. 2013;17(3):286-94.

97. Wahl CJ, Warren RF, Adler RS, Hannafin JA, Hansen B. Internal coxa saltans (snapping hip) as a result of overtraining: a report of 3 cases in professional athletes with a review of causes and the role of ultrasound in early diagnosis and management. Am J Sports Med. 2004;32(5):1302-9.

98. Wunderbaldinger $\mathrm{P}$, Bremer $\mathrm{C}$, Matuszewski L, Marten $\mathrm{K}$, Turetschek K, Rand T. Efficient radiological assessment of the internal snapping hip syndrome. Eur Radiol. 2001;11(9):1743-7.

99. Pelsser V, Cardinal E, Hobden R, Aubin B, Lafortune M. Extraarticular snapping hip: sonographic findings. Am J Roentgenol. 2001;176(1):67-73. 